\title{
Hotel Architecture for the Creative Class
}

By

Hanson Mak

A thesis submitted to the Faculty of Graduate and Postdoctoral Affairs

in partial fulfillment of the requirements for the degree of

\author{
Master \\ in \\ Architecture \\ Carleton University \\ Ottawa, Ontario \\ (c) 2013 \\ Hanson Mak
}


Library and Archives

Canada

Published Heritage

Branch

395 Wellington Street

Ottawa ON K1A ON4

Canada
Bibliothèque et

Archives Canada

Direction du

Patrimoine de l'édition

395 , rue Wellington

Ottawa ON K1A ON4

Canada
Your file Votre référence

ISBN: 978-0-494-94579-7

Our file Notre référence

ISBN: 978-0-494-94579-7
NOTICE:

The author has granted a nonexclusive license allowing Library and Archives Canada to reproduce, publish, archive, preserve, conserve, communicate to the public by telecommunication or on the Internet, loan, distrbute and sell theses worldwide, for commercial or noncommercial purposes, in microform, paper, electronic and/or any other formats.

The author retains copyright ownership and moral rights in this thesis. Neither the thesis nor substantial extracts from it may be printed or otherwise reproduced without the author's permission.
AVIS:

L'auteur a accordé une licence non exclusive permettant à la Bibliothèque et Archives Canada de reproduire, publier, archiver, sauvegarder, conserver, transmettre au public par télécommunication ou par l'Internet, prêter, distribuer et vendre des thèses partout dans le monde, à des fins commerciales ou autres, sur support microforme, papier, électronique et/ou autres formats.

L'auteur conserve la propriété du droit d'auteur et des droits moraux qui protege cette thèse. $\mathrm{Ni}$ la thèse ni des extraits substantiels de celle-ci ne doivent être imprimés ou autrement reproduits sans son autorisation.
In compliance with the Canadian Privacy Act some supporting forms may have been removed from this thesis.

While these forms may be included in the document page count, their removal does not represent any loss of content from the thesis.
Conformément à la loi canadienne sur la protection de la vie privée, quelques formulaires secondaires ont été enlevés de cette thèse.

Bien que ces formulaires aient inclus dans la pagination, il n'y aura aucun contenu manquant. 


$$
\text { A }
$$




\title{
Table of Contents
}

\author{
Abstract \\ Introduction \\ Part 1: History of Hotels \\ Part 2: Temporary/Permanent Stays \\ Part 3: Technology \\ Part 4: Portfolio \\ Part 5: Post-Script
}




\section{Abstract}

The hotel industry is constantly trying to capture untapped market segments. In the current Information Age, there is an emerging sociological change. David Brooks, a New York Times journalist, coined the term Bobos', for a new category of people who are educated, motivated individuals with high incomes but also consider themselves to be creative, with anti-mainstream cultural behaviors. This new Creative Class ${ }^{2}$, comprised by the Bobos look for places to be inspired.

The majority of existing hotels do not excite much beyond their superficial material finishes. Also, rooms for extended-stays are rigidly structured allowing no flexibility for personalization of space. The hotel for the Creative Class should be designed in such a way that encourages hotel guests to generate impromptu discussions, and creates opportunities for social interaction via exploration through the building. Could we design a hotel that addresses the above issues by investigating the needs of the Creative Class?

1 David Brooks, Bobos in Paradise (New York: Simon \& Schuster, 2000), 11. 2 Richard Florida, The Rise of the Creative Class, Revisited (New York: Basic Books, 2012), 8. 


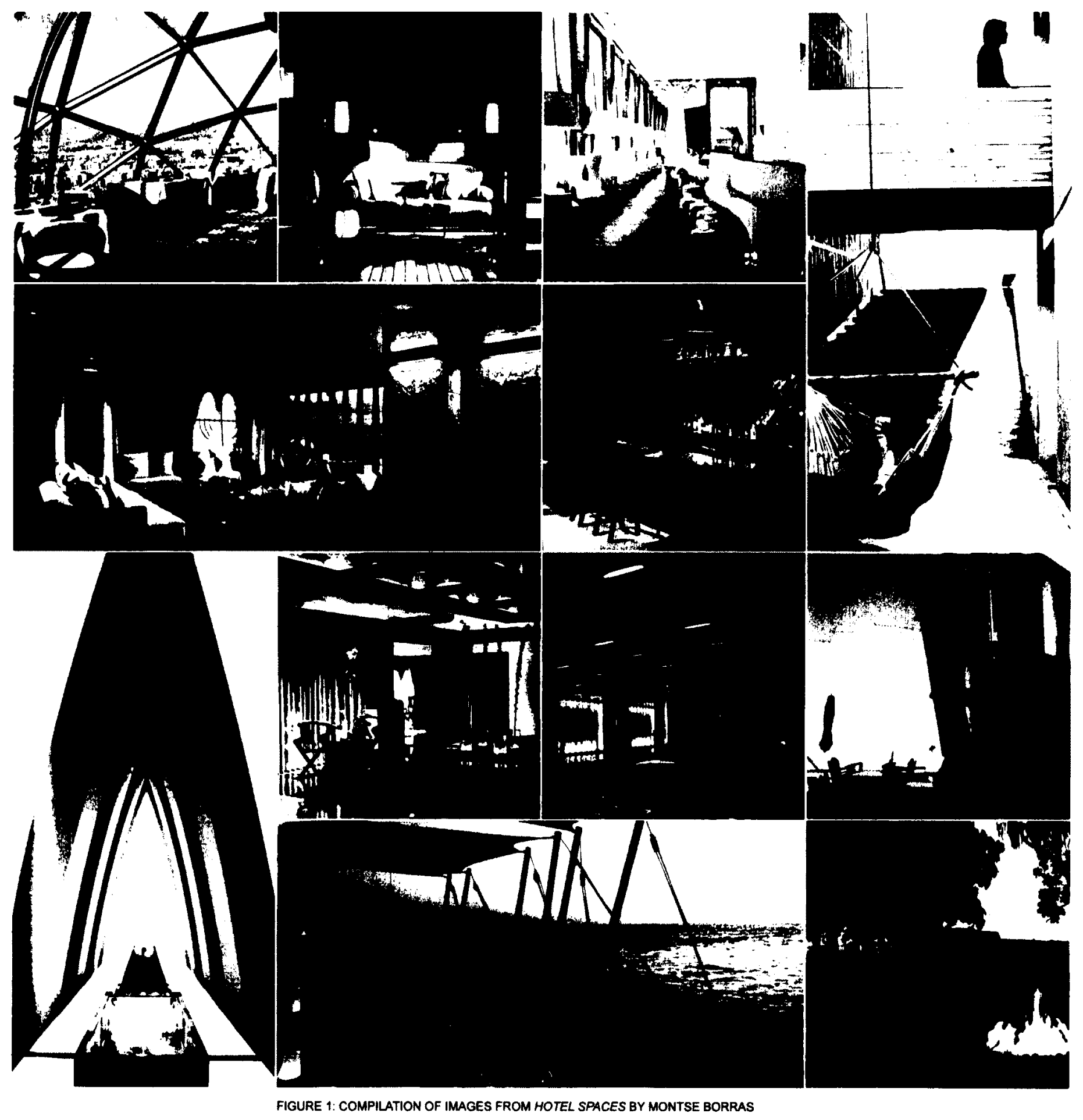


Private Bedroom

with outdoor

access

W Retreat \& Spa

Maldive
Curvilinear seating for casual meeting places

Mondrian Scottsdale, USA
Recessed wall displaying decora-

tion at the back

Bulgari Hotel \&

Resort, Bali
Trendy bar creating

a nice ambiance

W Retreat \& Spa, Maldive

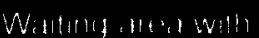

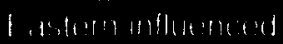

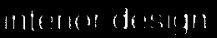

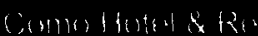

ante Pant Bhut.m
Metallic columns

placed in the lobby

Hotel Hesperia

Tower, Barcelona,

Spain
Unique facade with non perpendicular planes

Hotel Marques de Riscal, Spain (a)tan, 35 and if

WRumant \& Spr

Mislitive:
Destination point for soical gathering

W Retreat \& Spa Maldive

FIGURE 1A: DESCRIPTION OF IDEAS AND CONCEPTS RELATED TO IMAGES SHOWN IN PREVIOUS PAGE 


\section{Introduction}

This thesis explores the cultural behavior and lifestyle among a new emergent social class called the Bobos. Through the understanding of this subset of population, unique architectural ideas could also emerge to reflect the needs of this demographic. The term Bobos refers to "Bourgeois Bohemians", coined by David Brooks, a New York Times journalist, in Bobos in Paradise (2000) ${ }^{3}$. During the mid-20th century, the Bourgeois and the Bohemians could be easily differentiated. The Bourgeois were the upper class with inherited wealth from previous generations, and their parents' legacy helped secured them an education at an elite university. They were the people with family names that guaranteed them successes in the business world. The Bohemians, on the other hand, were the everyday artists and intellectuals that were considered 'hippies' during the 1960s." However,

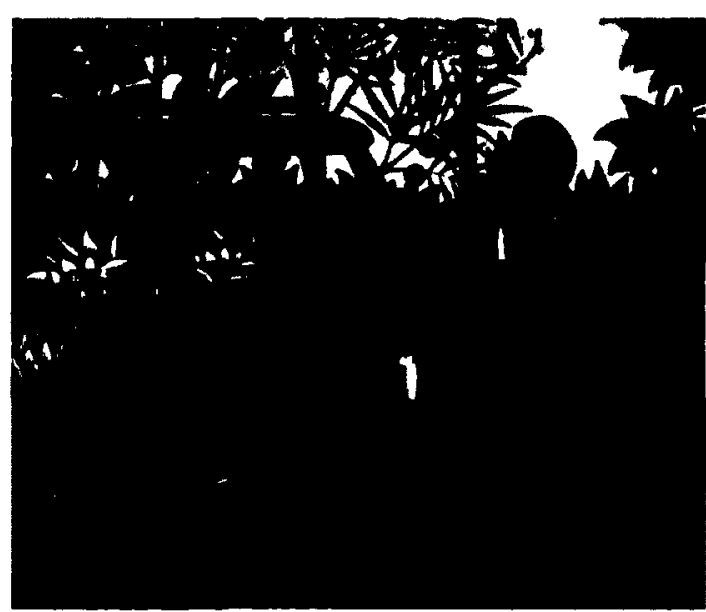

FIGURE 2: BOOK COVER IMAGE OF BOEOS IN PARADISE

with the rise of the Information Age, the Bourgeois and the Bohemians cultures became increasingly indistinguishable and thus the term Bobos is now used to describe the resultant hybrid social class. 


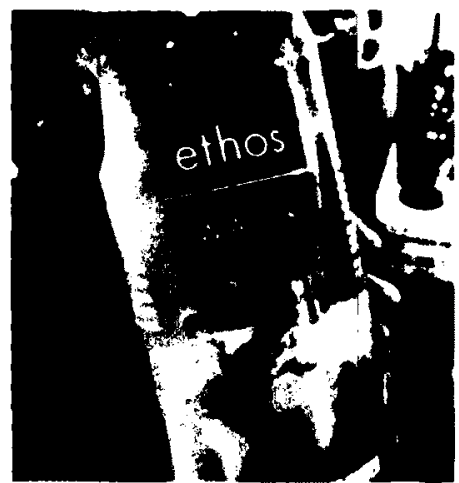

FIGURE 3: STARBUCKS ETHOS WATER

According to Brooks, Bobos are creators of their own success. They are hard-working people that made their way to universities without the help of a family legacy and successfully landed high paying jobs that they enjoy working in. They consider their jobs as part of a social mission with the mindset to better the lives of others. They are spenders, but prefer to only purchase items that contribute to a social cause or to their own spiritual well being.

"Bobo renounces accumulation and embraces cultivation. He must show, in the way he spends his money, that he is conscientious and not crass. The emerging code of financial correctness allows Bobos to spend money without looking like one of the vulgar Yuppies they despise. It's a set of rules to help them convert their wealth into spiritually and intellectually uplifting experiences." ${ }^{5}$

Through Bobos' educated minds, every purchase is a conscious decision. They will compare the price tag to the actual value of the item and if they support the manufacturing processes, story or the company behind it, they will make the purchase. For example, they will not support a company that uses child labor to create its products, but would be willing to pay a premium for a humanitarian cause such as buying a bottle of Starbucks Ethos Water, because they are aware that a portion of the sale will go towards providing developing countries with clean water.

5 Brooks, 85. 


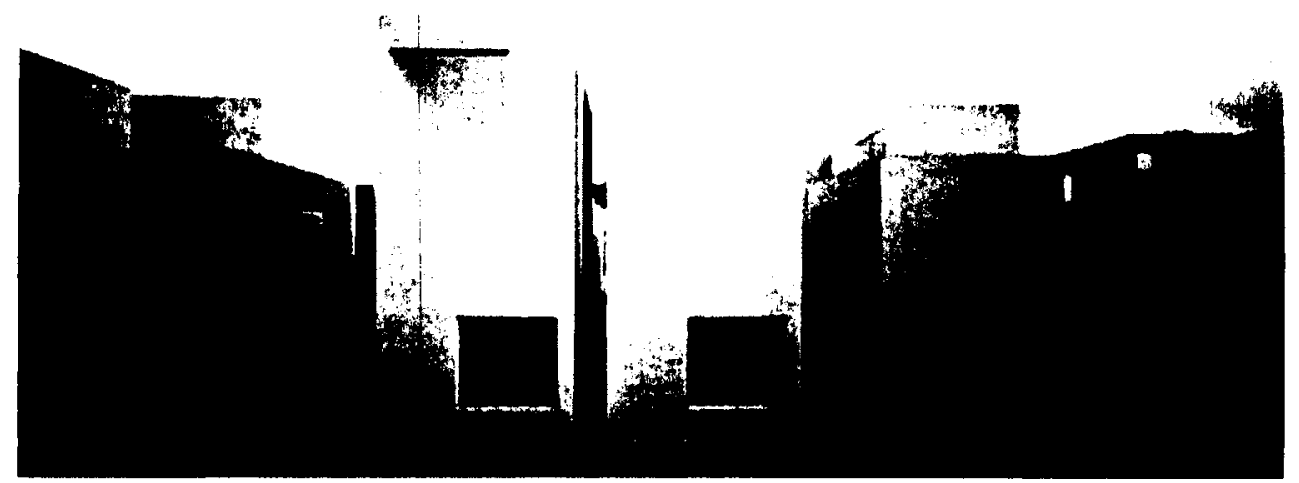

FIGURE 4: SANAA'S SEIJO TOWNHOUSES FACADE

It would also be absolutely justifiable for them to purchase an expensive household product such as a top of the line European made coffee maker rather than an average coffee machine because they have an appreciation for its craftsmanship and long-lasting qualities. They have a particular interest in purchasing consumer goods that are unique and rare to find, products not produced for the masses. Bobos are curators of their own possessions. ${ }^{6}$

When possessions are thoughtfully displayed within a space, a bland interior can become a curated environment that is intentional, organized and pleasing to occupy. Since everything Bobos own is carefully selected, the objects that they possess collectively reflect their lifestyle and tastes. Bobos like to display their successes in very subtle ways. This subtle curating of environment may also be achieved architecturally if the public is allowed to discretely glimpse the Bobo's home.

For example, Kazuyo Sejima and Ryue Nishizawa from SANAA (Sejima And Nishizawa And Associates) have tried to create architecture that encourages inhabitants to curate their own spaces. ${ }^{7}$ In the book Architecture at the Edge of Everything Else (2010) written by Esther Choi and Marrikka Trotter, SANAA's Seijo Townhouse had effectively captured the architects' social goals. The Seijo townhouse composed of plain

6 Brooks, 99.

7 Marrikka Trotter \& Esther Choi, Architecture at the Edge of Everything Else (Cambridge: MIT Press, 2010), 24. 


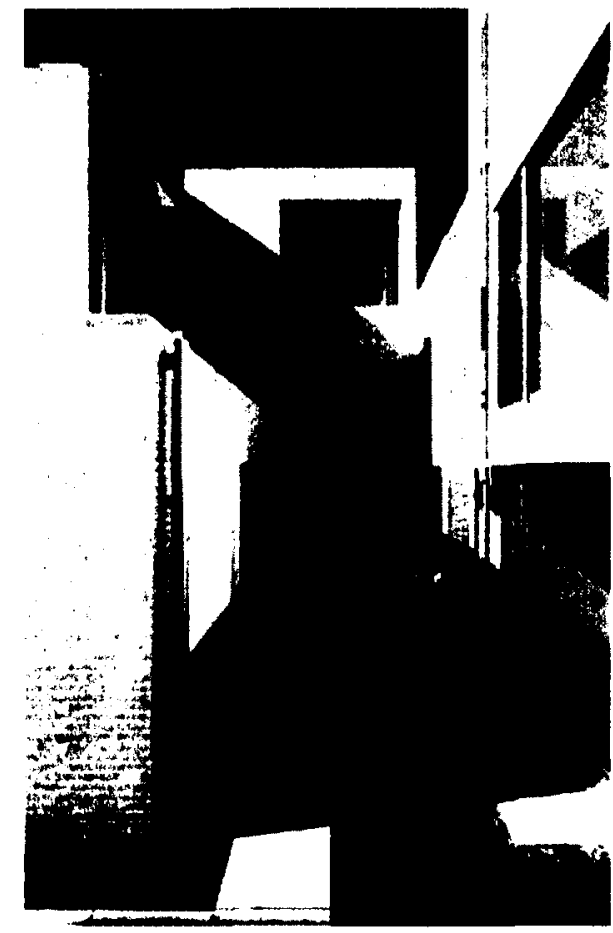

FIGURE 5 :

SANAA'S SEIJO TOWNHOUSES INNER COURTYARDS

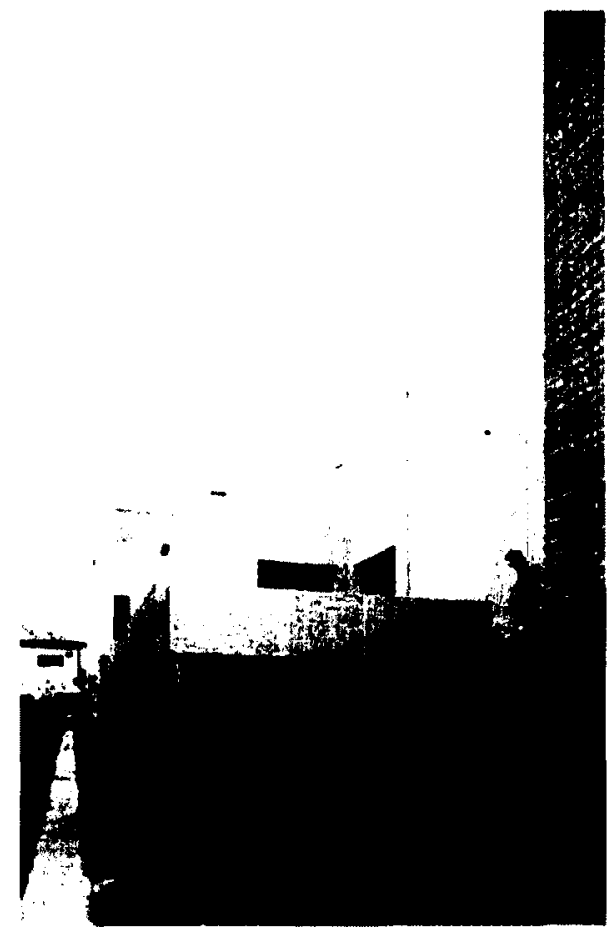

FIGURE 6 :

SANAA'S SEIJO TOWNHOUSES WITH LARGE OPENING THAT EXMIBITS THE ACTIVITIES INSIDE THE HOUSE 
white façades and basic rectilinear form complemented the architects' special emphasis on bridging private and public spaces together. The large window openings that fronted streets or across a neighbor's house allowed a showcase of the inhabitants' lifestyle as art. In affect, the inhabitants have to continually curate their own living quarters. At the same time, this openness and transparency allowed the interior to expand to the outdoor courtyards, whereby it creates opportunities to interact with the neighbors nearby.

However, it seems as though these moments of interaction are forced out of the residences and could be very uncomfortable at times. The deliberate design decision to make large open- ings in the front and back of the house so passersby can have a glimpse of the activities and environment inside constrains the inhabitants' behavior. Consequently, the inhabitants may feel that they have to look presentable at all times for others might see. Spaces of interaction between people should be triggered in public spaces where people are more open to meeting and socializing rather than in private spaces, like an individual's home.

The Seijo Townhouse is a prime example of how architecture allows "inhabitants (to) regulate their own behavior not as a response to a disciplinary authority, but as a way to fit within a socially determined aesthetic of life. ${ }^{n 8}$

8 Choi, 29. 


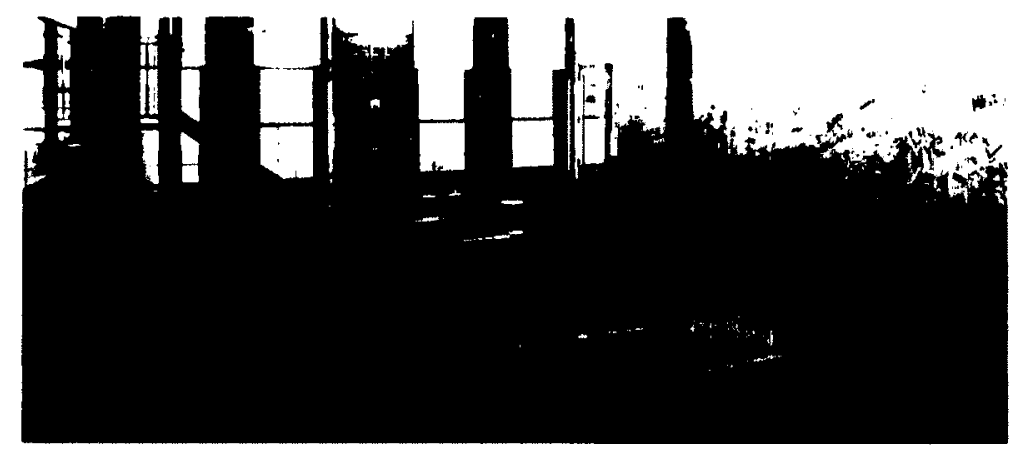

Inarguably, there is a growing trend towards creating environments that encourage interaction between people. This is especially true for office spaces. The hierarchical approach for business organization is a generation of the past. New office spaces are designed to inspire employees and strengthen their relationships with one another. According to Brooks, "now companies go on expensive retreats at which employees play noncompetitive games or wacky Olympics to build those relationships".

Companies such as Google are known for having the best office environments to work in. They have been awarded by Fortune magazine as one of the best places to work in for several years. ${ }^{10}$ Kursty Groves, author of I Wish I Worked There (2010), described sever- al strategies that they used to maintain a healthy working environment, while creating an atmosphere where people are encouraged to mingle with one another. One policy Google developed is that the planning of their office spaces has to ensure that no employee should have to walk more than 150 feet to get to a food station, whether it is the campus main cafeterias, a vending machine or office kitchens. They believed that these food facilities are a great place to continue brainstorming sessions and discussion. ${ }^{11}$

Like many other Silicon Valley companies, casual interaction and encounters are believed to promote collaboration between teams and generate more interesting ideas. Impromplu meeting places are designed throughout Google

9 Brooks, 129.

10 Kursty Groves, I Wish I Worked There! A look inside the most creative spaces in business (West Sussex: John Wiley \& Sons, 2010), 72.

11 Groves, 78. 


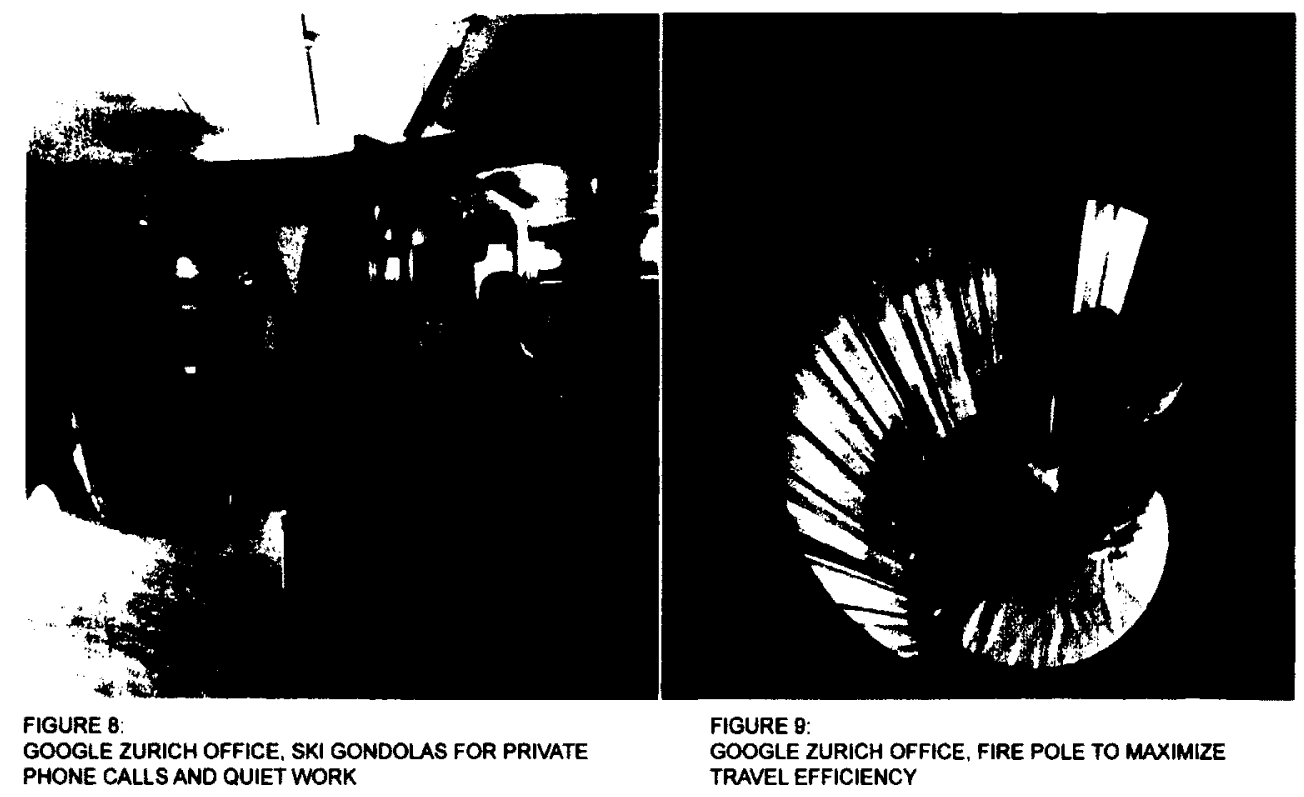

offices around the world to encourage

graduates voted Google as the number interaction between different teams and to generate informal conversations. For instance, Google placed various destination points for people to slow down and linger around. This could be an open space ranging from beanbags with a pool table to a full on in-house spa treatment. An area that is often overlooked but is a crucial part in making the occupants comfortable is their indoor air quality. Google uses commercial-grade air filtration systems that enhance their indoor air quality by $30 \%$ as compared to normal industry filters. ${ }^{12}$ Thus, it is no surprise that recent one dream company to work for.

Google campuses have various destination points within the building that employees can go to for casual encounters with colleagues. The architectural implication for these destination points should not only be driven by the assigned interior spaces. The primary circulation path should be considered as well and designed in such a way that people are encouraged to discover and explore various parts of the building. The simple architectural idea of encouraging users to explore the building

12 Groves, 76-83. 


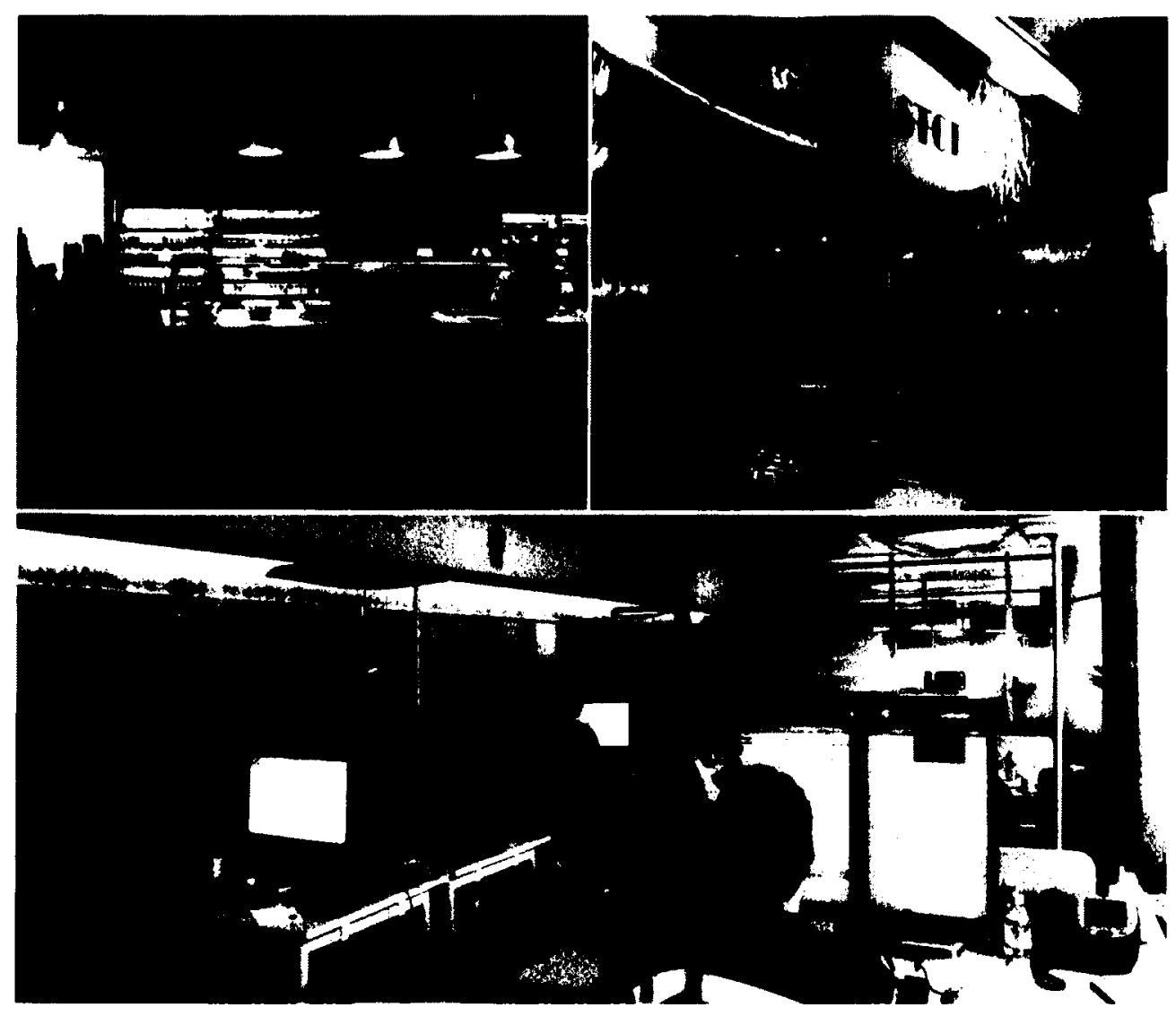

FIGURE 10:

GOOGLE CAFETERIA WITH NYC SUBWAY

FIGURE 11 (RIGHT): GOOGLE IT SUPPORT STATIONS INSPIRED SIGNS

PLACED THROUGHOUT THE BUILDING WITH MINI KITCHEN

FIGURE 12:

GOOGLE ZURICH OFFICE, WHITEBOARDS EVERYWHERE FOR BRAINSTORMING AND COLLABORATION. CASUAL MEETING PODS (EGG SHELL), ALLOWS RIDING BIKE WTHIN BUILDING FOR EFFICIENCY 
animates the environment and creates surprising impromptu conversational spaces.

Not only do companies like Google allow freedom and flexibility for its employees, office culture that is brewed this way allows staff to be more productive and innovative as a result. Unsurprisingly, Richard Florida, an expert at urban and social trends, explained in The Rise of the Creative Class: Revisited (2012) that even in the late 1990s, young adults already prefer to work in jobs that offered them freedom and flexibility. A machinist from this time was highly praised and regarded as an excellent profession that guaranteed stable income working in a fixed schedule. Although demands in the industries for machinists at the time were high, there was only a small amount of people who were willing to go through the training and fill these positions as their life career. ${ }^{13}$

However, the day-to-day grind of a machinist is repetitive and once the skills are honed, the job is no longer challenging or stimulating. Accordingly, there is an increased preference towards working in a job that offers both flexible hours and creative freedom. Florida, during his lecture at Carnegie Mellon asked students if they would rather work at places where the job gave them a stable income with regular work hours or if they prefer working at places such as a hair salon that gave them creative freedom but their finan-

13 Florida, 65-67. 
cial income were less predictable. It turned out that the vast majority of them preferred working at a hair salon, for its flexibility in work hours and expression of personal creativity. Florida explained that it's best if individuals could have "input into the design of the workplace ${ }^{14}$ The freedom to experiment and to rearrange a space to maximize workflow liberated the students. This is not to say that every graduate prefers this but a large percentage of them fall into the category that Florida classified as the Creative Class.

In America, about one third are defined as the Creative Class ${ }^{15}$ (similar to David Brooks' term of Bobos), they are highly educated with a university degree, chose to work in jobs that benefits the society or humanity in some magnitude and are careful in acquiring possessions that are expensive and are rare to find.

Then, given the existence of the Creative Class, there should already exist companies that cater to them. In fact, in the worid of consumerism, there are numerous products that are designed for them. It could be argued that products such as iPhones or computers manufactured by Apple are gadgets that the Creative Class craves for due to their aesthetics in design and engineering. In architecture however, there are only a few architectural typologies that the Creative Class often come in contact with, one of them being hotels.

The architectural programming of hotels can encapsulate a vast range of needs

14 Florida, 73.

15 Florida, 8. 


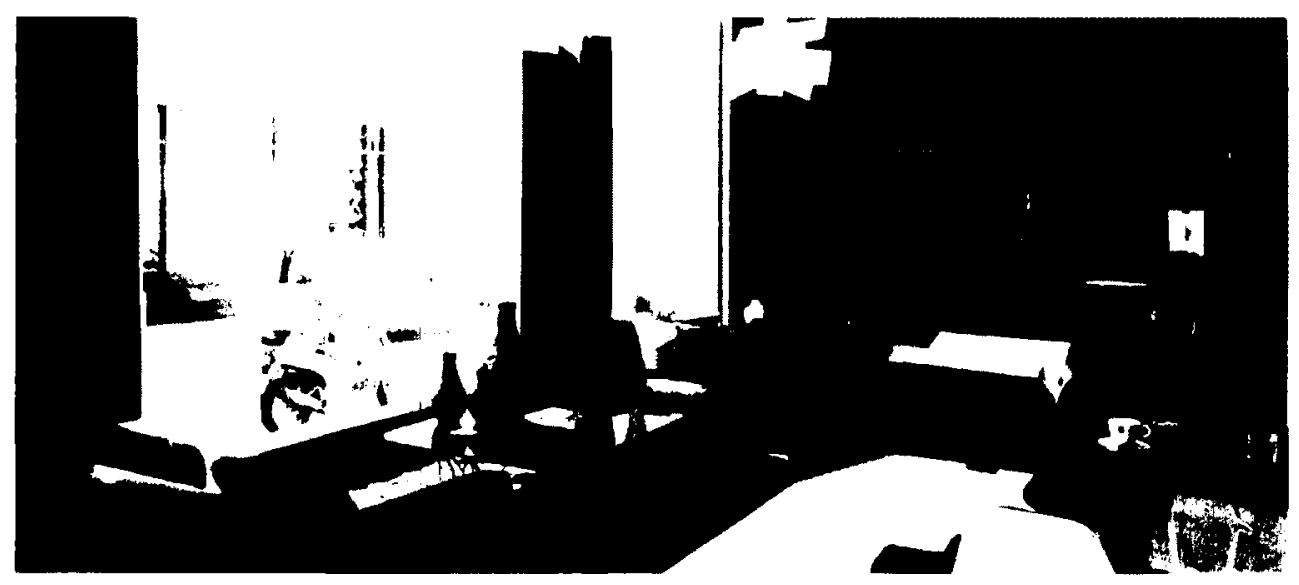

FIGURE 13: LE MERIDIEN BARCELONA, THE 'LE MERIDIEN HUB'

and activities that people do in their daily lives. These activities include eating, sleeping and working which occupy the majority of people's schedules. For these reasons, it makes logical sense to develop a project and implement architectural ideas within a hotel typology. However, first we need to investigate what has already been done in the hotel industry to attract the Creative Class clienteles.

Le Meridien Hotel is an example of a Hotel chain that specifically targets this group of people mentioned above. The hotel, acquired by the Starwood Group in 2006, consulted with Florida to elevate their brand to uniquely serve the Creative Class. Le Meridien Hotel has many accommodations situated in major countries around the world. One of its strategies in differentiating their hotels from one city to another is the creation of a hotel library that offered books on local arts, music, architecture and culinary cuisine to travelers. This allowed visitors a convenient way to discover local culture and activities. Other ways that Le Meridien Hotel tried to bridge their hotel to the arts is the commitment that they have with nearby museums. The hotel room card presented to guests doesn't just function as a key to a room or to the hotels recreation facilities, it also offer access to different museums around the city. The graphics displayed on the card are works of arts from local artists. A curator hired by the hotel specially details the placement of every painting/ 
sculpture showcased in the hotel. ${ }^{16}$

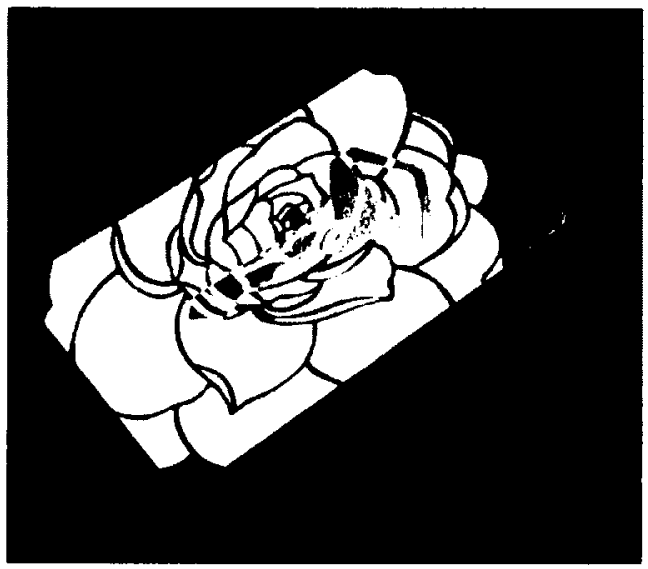

Although these small changes could be considered as innovative in the hotel industry, there really isn't much change architecturally. The experiences of the spaces from the lobby to the hotel rooms are still relatively similar to what exists in traditional hotels. In order to find innovative architectural solutions for the Creative Class, the hotel must be completely redesigned with circulations that encourage guests to interact with each other and architectural strategies that are attuned to their lifestyle.

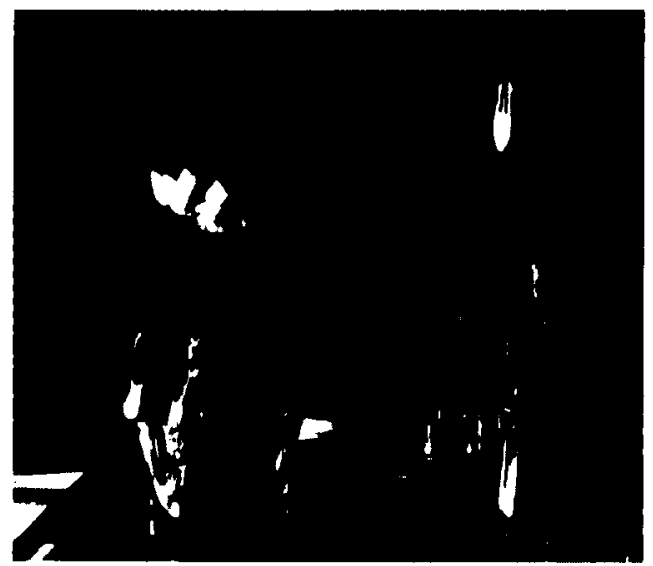

Thus far we have discussed the culture, interests and behaviors of a new emergent social group as identified by Florida and Brooks and what has already been done architecturally to captivate, challenge and motivate these individuals. In the next portion of this paper, we will examine how hotels came about and the industry's evolution to date. In learning the lessons from the past, we can better envision the next iteration of design change.

16 Stanwood Hotels \& Resorts, Starwood Hotels \& Resorts, 03 Dec 2012 <http:// www.starwoodhotels.com/lemeridien/lm100/artist.html?id=FLORIDA>. 


\section{History of Hotels}

The book Hotel: An American History written by A.K. Sandoval-Strausz, introduces the concept that the architectural typology of hotels in America developed circa 1800's. According to the author, the idea of hotels may have come about when the then newly elected President George Washington made his national tour across America. Washington understood that his success to unify the nation depended on his every action and thus decided to stay in public houses for the tour rather than in private hospitality where the public might view it as favoritism. ${ }^{17}$ Public houses, also called taverns and inns were generally private homes or buildings that were converted to accommodate travelers. The condition of these spaces lacked privacy and cleanliness. The vernacular exteriors were often indistinguishable as a public house from its neighboring buildings. ${ }^{18}$ In short, these early accommodations were not purpose built for their function. The first generation of hotels was built in the early 1800's with Boston Exchange Coffee House (Figure 16) being the very first to be completed in 1809. Several earlier projects had been proposed and partially constructed but were never completed. ${ }^{19}$

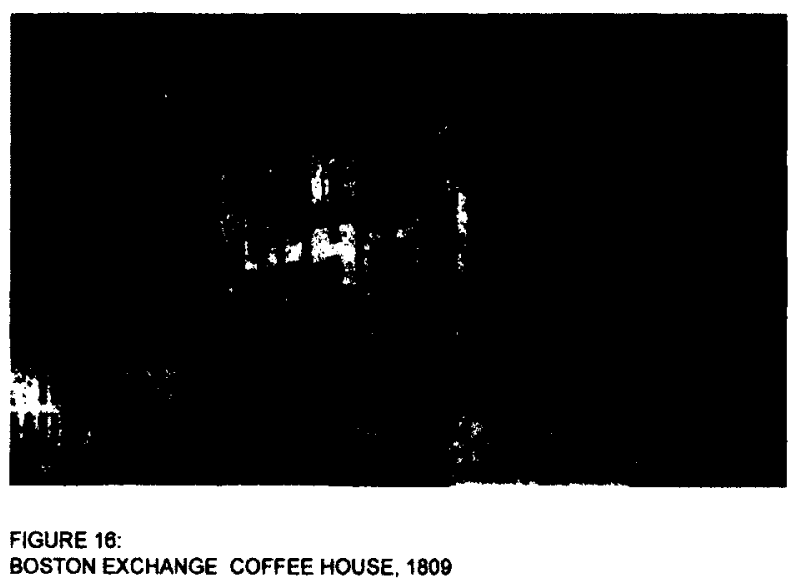

17 A.K. Sandoval-Strausz, Hotel: An American History (Devon: Duke \& Company, 2007), 13-15.

18 Sandoval-Strausz, 17.

19 Sandoval-Strausz, 21-29. 
The first generation of hotels was targeted towards the upper class with grand ballrooms, coffee/tea rooms and meeting rooms. The overall goal was to vastly improve the condition of what its predecessors had to offer. However, the emerging industry quickly came to a realization that people of different social classes would occupy these public spaces and as such, hotel architecture began to evolve to have "multiple parlors, meeting halls, ballrooms, coffee rooms and bars for compartmentalized public sociability". ${ }^{20}$ In turn, this led to the creation of a second generation of hotels that aimed to serve the middle class and the common man.

The gradual changes to hotel design can be observed in the evolution of its floor plans. As mentioned earlier, the very early public houses were shared spaces within a family home (Figure 17). Public houses then moved from the basic bungalow type houses to multi-stories family dwellings (Figure 18). It was economically viable since the family who lived there worked to serve their guests. The next development of these household buildings led to a total reconfiguration in its design (Figure 19). Bedrooms were placed side-by-side in the upper floor with much larger parlors, kitchen and dining rooms at the ground level to better accommodate groups of people at a time. ${ }^{21}$ As demand grew, public houses had to become institutionalized and new architecture had to be invented like the Boston Exchange Coffee House where teams of staffs were needed to properly run the business. ${ }^{22}$ In the early nineteenth century, 

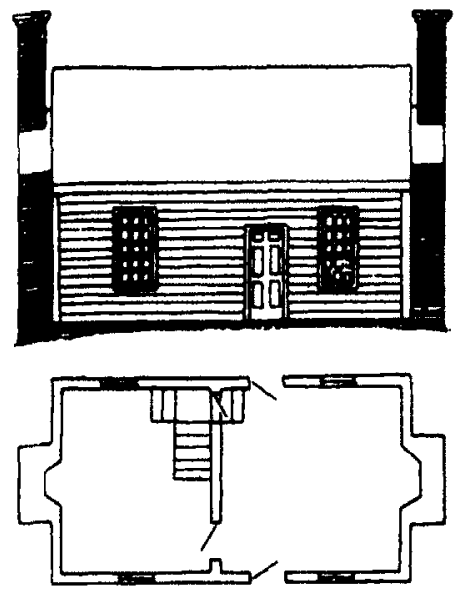

FIGURE 17

A TYPICAL BUNGALOW HOME THAT CAN ACCOMODATE TRAVELERS

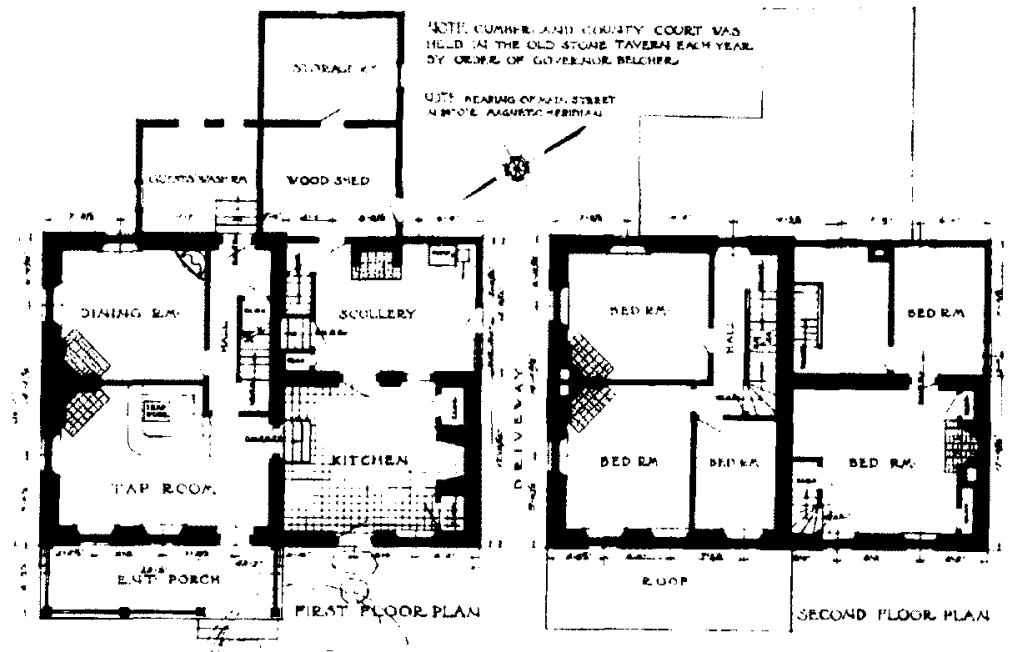

FIGURE 18:

EARLY AMERICAN TAVERNS WTH DIMSION OF SPACES THAT CAN ACCOMODATE LARGER GROUPS

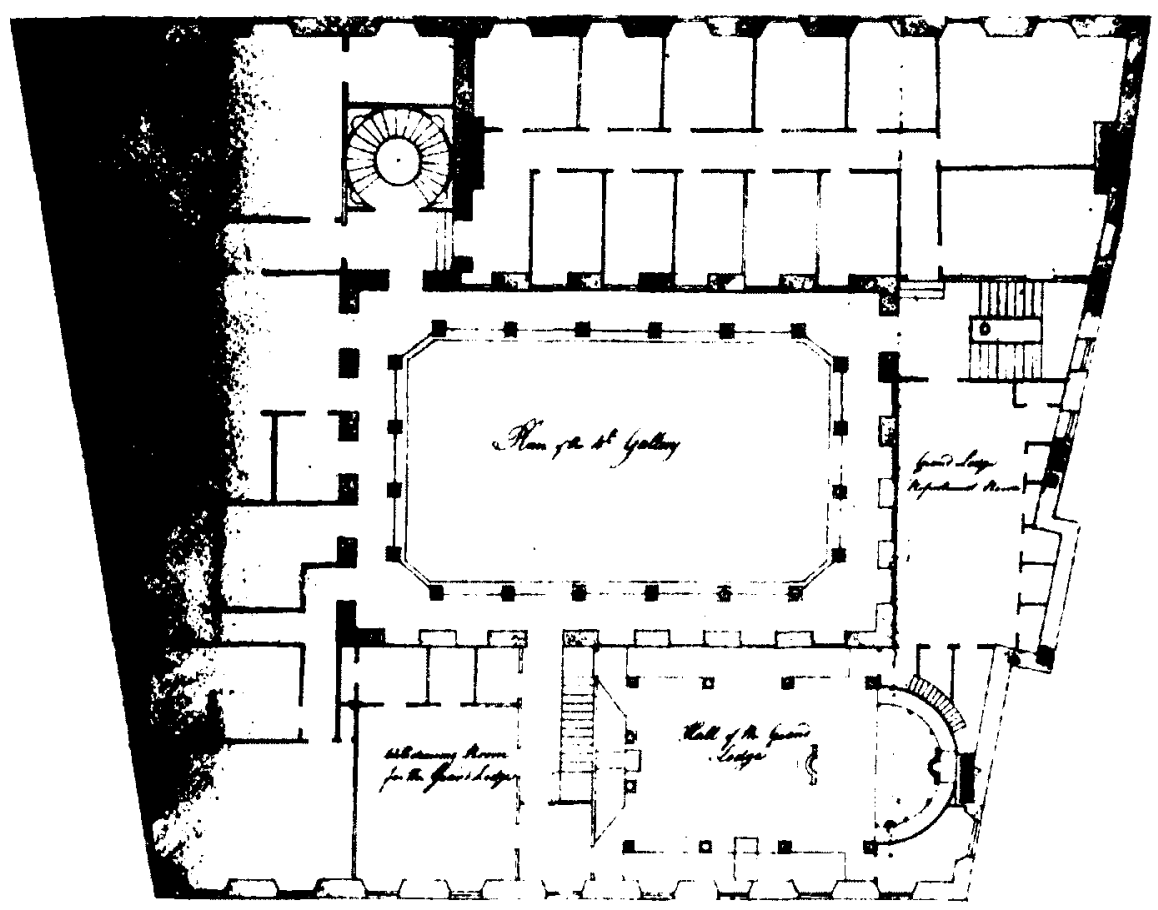

FIGURE 19:

BENJAMIN'S COFFEE EXCHANGE HOUSE, 1809

RECONFIGURATION OF ROOMS SO THAT ROOMS HAVE CORRIDOR ACCESS

INSTEAD OF HAVING ROOMS OPENING ONTO ANOTHER ROOM 
architects experimented with the hotel architecture, discarding what isn't needed and expanding what functioned well. It later led to development of the double loaded corridor system such as the one in Tremont House of 1829 , it was a leap in design that functioned better than opening one room onto another. ${ }^{23}$

Evidently, the design evolution of hotel was driven by cultural shifts and changes to our social behaviors. As mentioned before, in the early days, each room had a very specific function. Then design changes had to be made to accommodate multiple rooms to deliberately separate different people of different social classes. However, in modern society, people are willing to engage and interact with others without prejudice to background, culture and education; even organizations have a trend towards working horizontally within offices rather than vertically. There is a cultural shift towards a more transparent environment, such as our desire for open concept interiors. The design of public spaces will need to stimulate the minds of those who occupy it. In the case of private spaces, such as an individual's hotel room, it is critical to understand the needs of the traveler, especially one from the Creative Class.

23 Sandoval-Strausz, 147. 


\section{The World Traveler}

Even in the modern day, the idea of living in a hotel can be quite alluring to people. Some individuals, like multi-billionaire Nicolas Berggruen for example, sold his mansion and luxury condos in favor of staying in hotels. Although he acquired the world's largest collection of Pablo Picasso paintings among many other things, he only carries a bag of clothes and his blackberry with him while traveling in his private jet. ${ }^{24}$

The homeless billionaire stores clothes and other belongings at various hotels that he frequents. The idea of acquiring things had lost interest to him. When Berggruen was asked by a Wall Street Journal reporter why he lost the appeal in possessing things, he answered:

"Whatever I own is temporary, since we're only here for a short period of time. It's what we do and produce, it's our actions, that will last forever.

That's real value." 25

Berggruen, like the rest of the Creative Class wants to create an impact on society, and consequently value this more than material possessions.

For business travelers that stay at a hotel for months at a time, our current architectural model of extended-stay hotel works efficiently to a certain extent. Over the years, hotel interior have changed according to the social culture at the time. Inarguably, our world has become more transient than ever before. People who travel to a city for an extended period of time whether it is for studies, business or for personal pleasures, packing, storing and transporting their personal items can be a headache after months of accumulation of items. Even for minimalistic living like the

24 Business Insider, The High-Flying Life of 'Homeless Billionaire' Nicolas Berggruen, 16 Dec 2011, 20 Jan 2013 <http://www.businessinsider.com/homeless-billion aire-nicolas-berggruen-2011-12?op=1>.

25 Robert Frank, The Homeless Billionaire - The Wealth Report - WSJ, 19 May 2008, 20 Jan 2013 <http://blogs.wsj.com/wealth/2008/05/19/the-homeless-billionaire/>. 


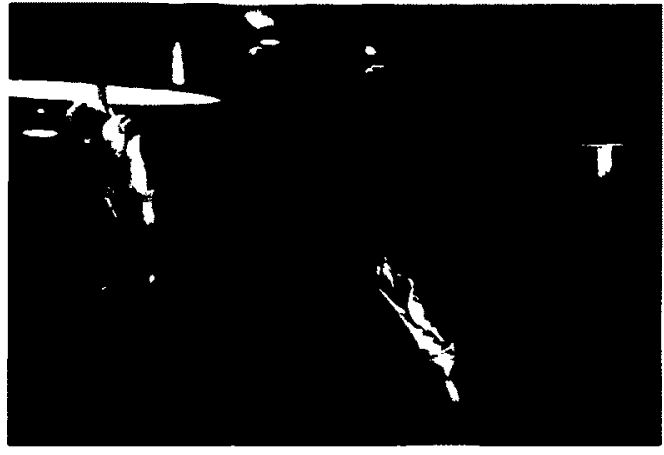

FIGURE 20:

NICOLAS BERGGRUEN IN HIS HOTEL ROOM AT

CARLYLE HOTEL, NEW YORK, 2011 homeless billionaire, storage for personal stuff is still an essential. The idea for private spaces, such as the hotel room, should continue to respond and adapt to the changes in our social behavior. Architecture should adapt to its users through design rather than the other way around. The intervention for a new type of extended-stay hotel architecture will be based on curatorial architecture whereby the architecture encourages hotel guests to make their room more personal. Thus, in the following section, transportable units for temporary stay will be observed and extended stay hotels will be analyzed to understand the reality of the market demands and condition. 


\section{Temporary/Permanent Stays}

There are two main types of residences where individuals can stay depending on their preferences: Temporary and Permanent shelters. Architecture such as Pop-Up hotels and structures that can be disassembled and reassembled for transportation are categorized as temporary. Pop-up hotels are used in festivals where they are only set up for up to a week or for the wealthy individuals who travel to exotic locations and need shelter.

Andrea Zittel, an accomplished designer who has exhibited her work at the Venice Biennale and the Whitney Biennials, designed and created several prototypes of compartment units that are transportable and could be reassembled easily by one or two people (Figure 21). Her designs all provide the basic necessities needed to live comfortably. The unit themselves offer

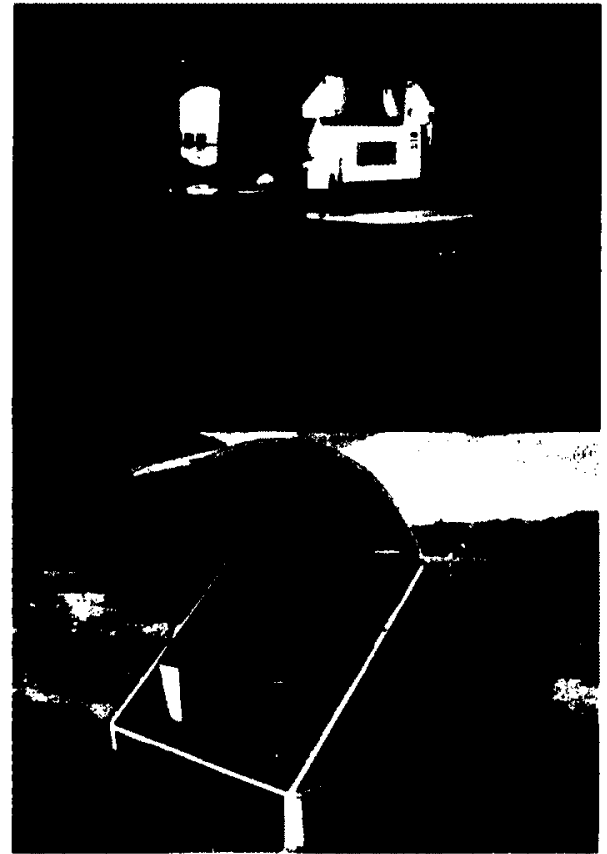

FIGURE 21:

PORTABLE ARCHITECTURE PROTOYPES BY ANDREA ZITTEL

shelter from the elements, a sleeping area and storage spaces for cooking supplies and personal items. These portable modules are tested and used by 
FIGURE 22

SLEEPING PODS INA

CAPSULE HOTEL

her friends and collaborators in remote West Coast deserts where the climate is appropriate for the built structures. Her vision for these projects is to develop "qualities that create independence for the owner and user: Compactness, Adaptability and Transportability." ${ }^{26}$ The three listed attributes are also applicable for the hotel guests.

For the Creative Class travelers who stay at different cities for a lengthy period of time, their hotel room is often the only place where they can call home for the entire trip. As such, these hotel rooms should allow users the freedom to rearrange and decorate their space with items that are of value to them. In Rethinking Design and Interiors written by Shashi Caan (2011), she explained that designers and architects have the ability to plan and design volumes that fulfill programmatic requirements and

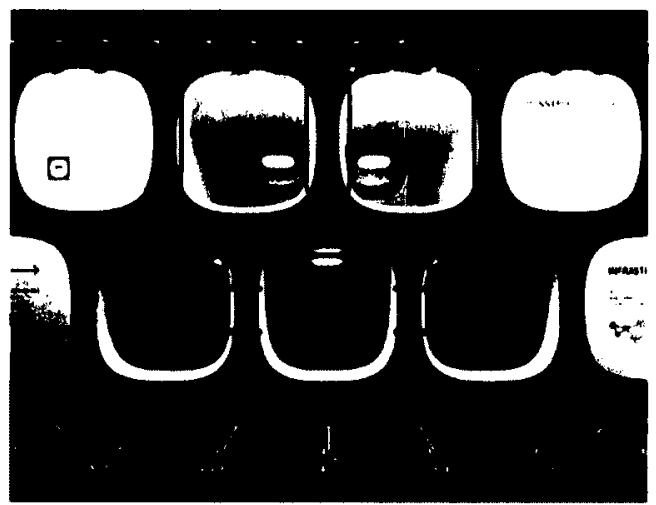

also plan ahead for future occupants. However, she also expressed that "beyond these functional requirements are the factors that cater to psychological needs, stimulating the mind and senses, and uplifting the human spirit." $^{27}$ These psychological concerns need to be addressed especially for an extended-stay hotel where guests only have their belongings to depend on for comfort in an unfamiliar setting. During these long period of stay, purchases (of rarity or not) will inevitably be made and the accumulation of items will increase over time. Thus, the design of hotel rooms should allow an easy process for the guests to display, store and transport personal items.

In the permanent category, the sizes of these personal spaces can range from a small bed to a full condominium suite. Capsule hotels, originated from Japan

26 Jennifer Siegal, More Mobile: Portable Architecture for Today (New York: Princeton Architectural Press, 2008), 46.

27 Shashi Caan, Rethinking Design and Interiors: Human Beings in the built environ ment (London: Laurence King Publishing, 2011), 112. 
have sleeping pods that are stacked on top of each other and are placed side by side to maximize the number of guests within the property. Usually, they are for accommodating travelers for 1 to 3 nights. There are also hostels and bed and breakfast, where the home environment created by these establishments is more inviting for guests to be more social and mingle with one another. People from all over the world travel to these accommodations and when they have the chance to gather in public spaces such as the lobby, Internet lounge or dining hall, they are more susceptible to chat and share their stories. The hotel for the Creative Class is no different in the way that travelers are coming from different parts of the world. The architectural design will need to recreate these social experiences by offering exciting opportunities for people to meet informally. These conversations should seem like serendipitous encounters, when really they are instigated by the design of the spaces.

Hotels, even Le Meridien Hotel, are often designed for accommodation from a couple days to up to a week's stay. However, in order to design a hotel that reflects a lifestyle pattern, we need to understand the current design of extended-stay hotels. Case studies are drawn from Marriott's extended-stays hotel brands: TownePlace Suite and Residence Inn. 


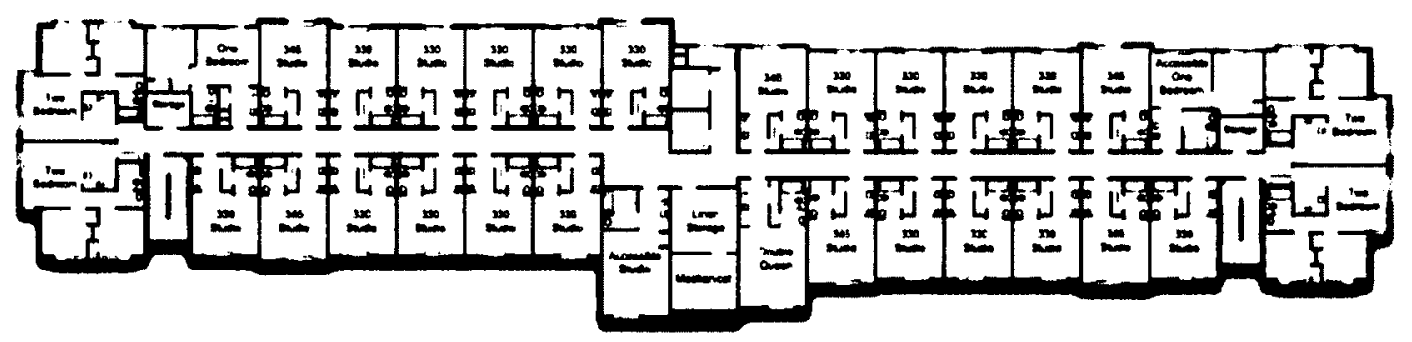

FIGURE 23

MARRIOTT TOWNEPLACE SUITE TYPICAL FLOOR PLAN

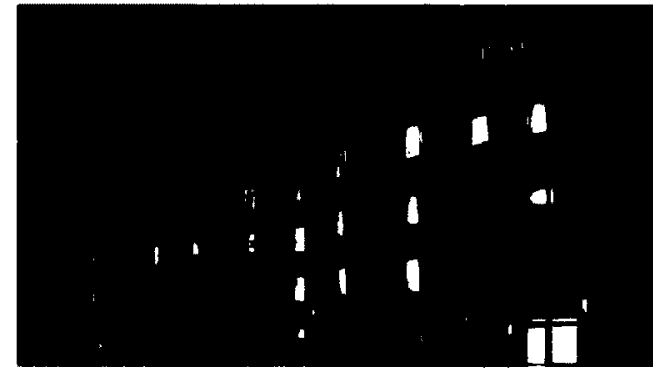

FIGURE 24:

MARRIOTT TOWNEPLACE SUITE TYPICAL EXTERIOR
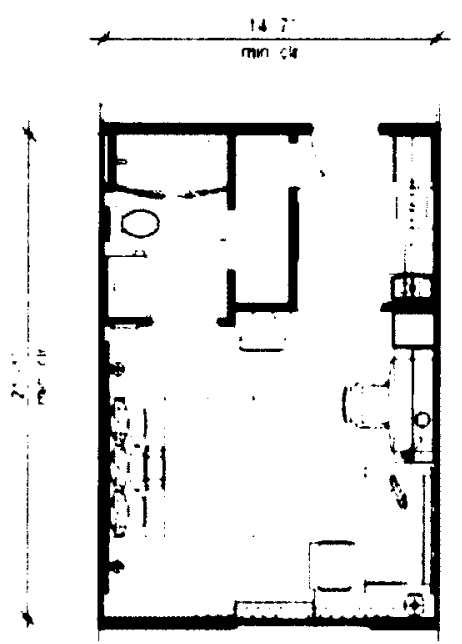

FIGURE 25:

MARRIOTT TOWNEPLACE SUITE

TYPICAL STUDIO ROOM
TownePlace Suite targets people who are value conscious and would rather stay in a hospitality that is economical yet practical. The need for fancy recreational facilities, restaurants and bars are not necessary for its clients. As a design guideline set by the hotel chain, a typical layout of this hotel is shaped longitudinally with a double loaded corridor serving as circulation spaces for rooms on both sides. The building stands 4 stories high with parking spaces around the perimeter of the property. The majority of the rooms are studio rooms at a mix of $80 \%$ and availability for one bedroom at $5 \%$ and two bedrooms at $15 \%{ }^{28}$ The layouts of the rooms are typical condominium floor plans with a small kitchen in the entrance area. 

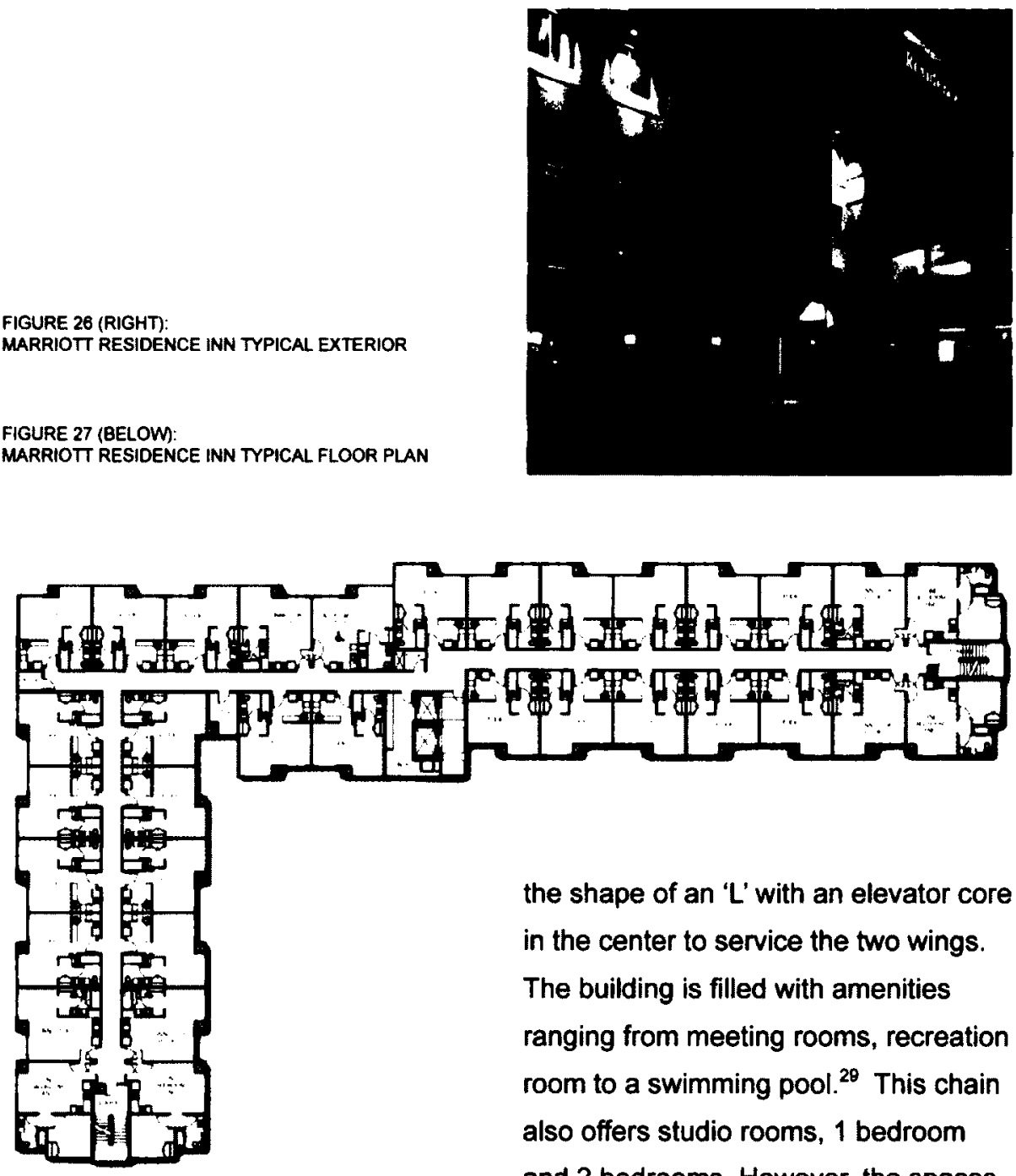

In comparison, Residence Inn, also by the Marriott, targets a different demographic than the TownePlace Suite brand. Their targeted clienteles are the frequent business travelers who want more comfort to rest and work in. The typical layout for this hotel chain is in the shape of an ' $L$ ' with an elevator core in the center to service the two wings. The building is filled with amenities ranging from meeting rooms, recreation room to a swimming pool. ${ }^{2 \theta}$ This chain also offers studio rooms, 1 bedroom and 2 bedrooms. However, the spaces are carefully planned to accommodate a full kitchen and a spacious sitting area that can comfortably entertain guests if needed. Overall, the Residence Inn rooms have a higher square footage when compared to similar TownePlace Suite rooms. 


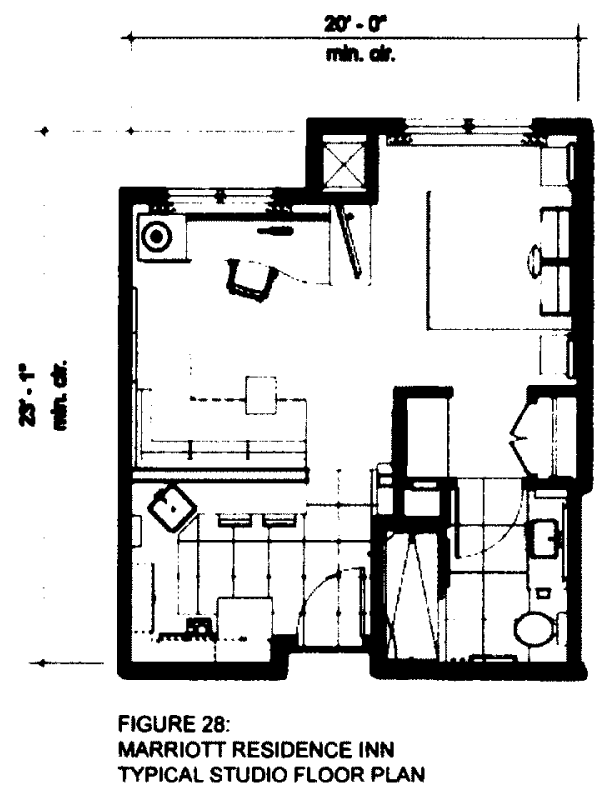

With the understanding that the majority of extended-stay hotel rooms are comprised of studio rooms with a kitchen that opens onto the living and sleeping area, this will become the basis for the portfolio's hotel room design. For the design solution of other architectural challenges as discussed previously, it would require technological solutions. For example, the Creative Class likes to be challenged and inspired but the mundane circulation for a typical building with vertical circulation core is predictable and unexciting for them. If we can develop a new technological innovation to address the building's circulation core, then the building could become inspiring to explore. Accordingly, research on the current technological capabilities that are relevant to the design presented in the portfolio will be studied to support that the ideas could in fact be achieved. 


\section{Technology}

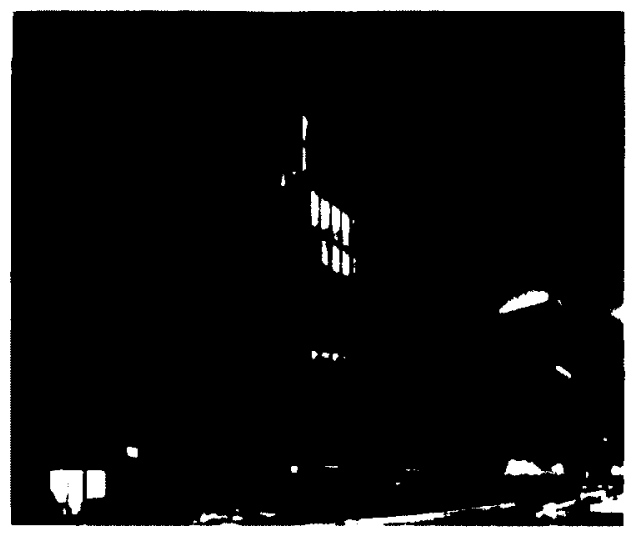

FIGURE 28

EXTERIOR OF SPERONE WESTWATER GALLERY BY FOSTER + PARTNERS

The Sperone Westwater Gallery located in the heart of New York City features a moving art room that animates the building façade. The intent of this design was to allow galleries at different floors the possibility to expand into the moving gallery when needed. The moving gallery connects all 5 floors of private and public gallery spaces. Additional elevators and stairs at the back are used for the main circulation and thus allowing the moving gallery to park on a specific floor based on its daily activities. ${ }^{30}$ The moving room operates on hydraulics and the works of arts featured inside are carefully curated. The concept of a transportable 'curated box' that can store or display people's possessions within a hotel room will become part of the portfolio design. For public spaces, elevators that can go on a diagonal will be developed in the portfolio and thus, non-conventional elevators will need to be utilized.

30 ArchDaily, Sperone Westwater Gallery / Foster + Partners, 22 Sep 2010, 03 Apr 2013 <http://www.archdaily.com/78827/sperone-westwater-gallery-fos ter-partners-2/>. 


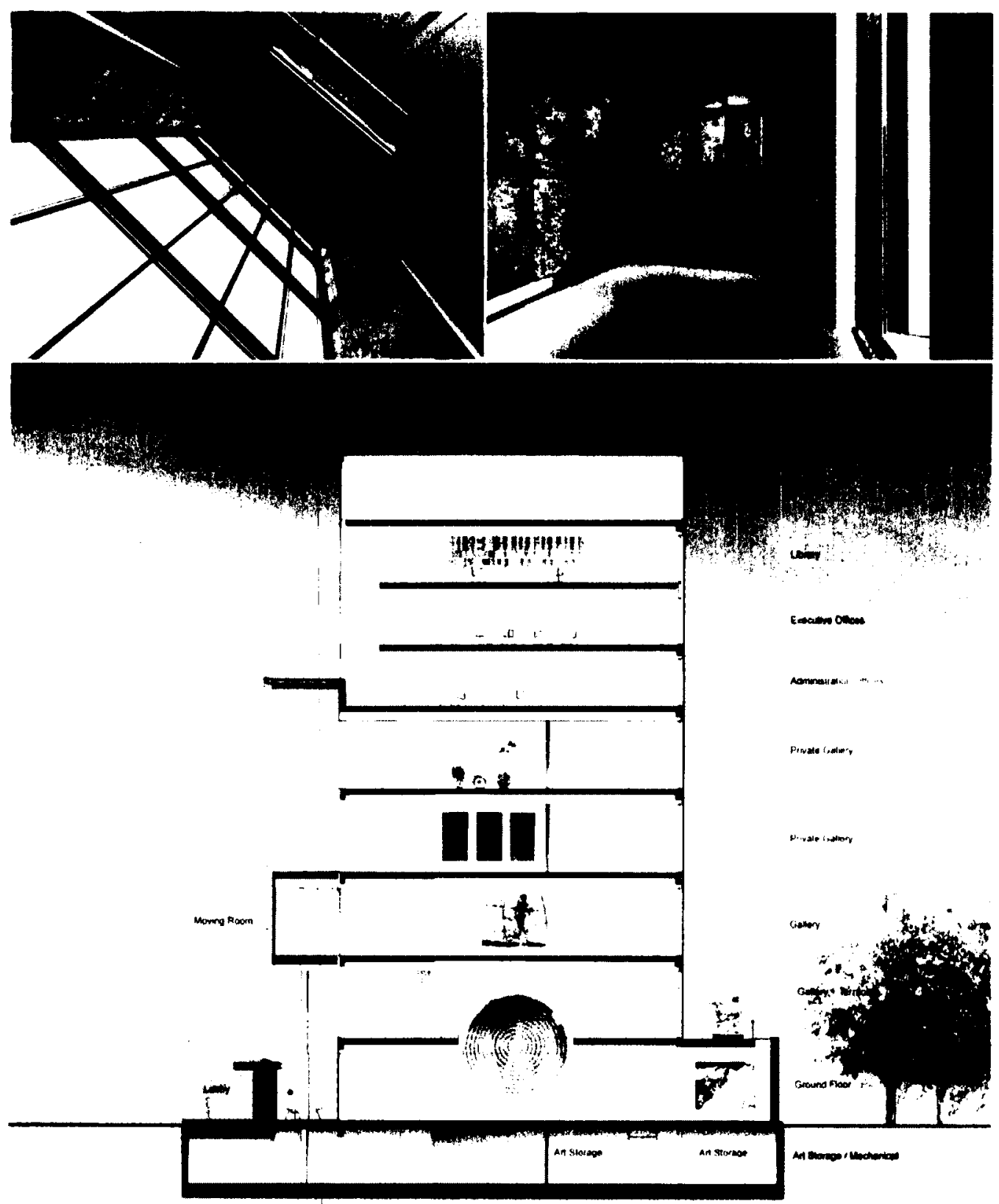

FIGURE 30

IMAGE SHOWING THE UNDERSIDE OF

THE MOVING GALLERY WITH HYDRAULIC

PUMPS

FIGURE 32 (BOTTOM)

SECTION THROUGH THE BUILDING DEPICTING THE MOVING GALLERY AS

THE FEATURED SPACE AND ADDITIONAL ELEVATORS ON THE BACK OF

THE BUILDING
FIGURE 31 (RIGHT):

NTERIOR SPACE OF THE MOVING GALLERY WITH INSTALLATION PIECES ON THE SIDE OF THE WALLS 


\section{Non-Conventional Elevators}

The conventional set up for an elevator runs vertically straight up, perpendicular to the ground. This upward movement translates into a resultant force that is exerted down on people's feet. People have traveled in such environment many times before and the experiences are generally very predictable. Some exceptions may be the acceleration speed of the elevator cabs or the views that the elevator shaft may offer as it travels up from floor to floor. However, non-conventional elevators such as the 16 inclined elevators installed in Las Vegas Luxor Hotel in 1990s provides a completely different ride experience that is exciting for most hotel guests. ${ }^{31}$ In the Vertical Transportation Handbook written by Robert Caporle and George Strakosch (2010), it revealed that the building codes for inclined elevators did not anticipate high-speed elevators before the Luxor project. The old building

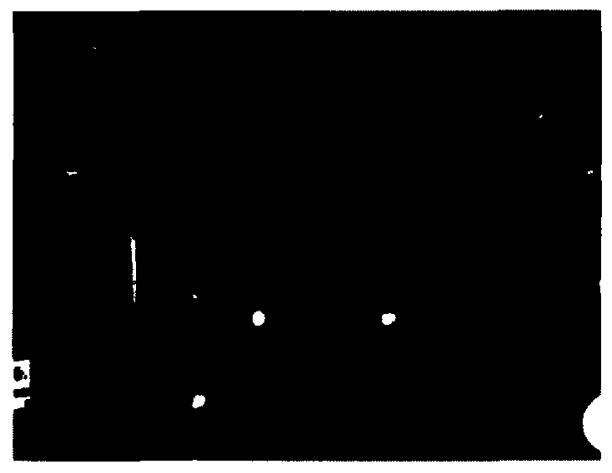

FIGURE 33:

INTERIOR VIEW OF THE LUXOR HOTEL ATRIUM SPACE WITH INCLINED ELEVATOR ENCLOSURE PROMINENTLY FEATURED

codes had a limit of maximum horizon-

tal peak of $0.5 \mathrm{~g}$ for a few milliseconds; otherwise the horizontal force is too large that the passengers will be thrown off balance. With the design of Luxor's high-speed inclined elevators, codes had to be updated and it was determined that the $0.5 \mathrm{~g}$ limit was outdated. Thus, the code was changed to present day's maximum horizontal force of $0.1 \mathrm{~g}$ for 125 milliseconds with gradual acceleration and deceleration or $0.25 \mathrm{~g}$ for emergency stops. ${ }^{32}$

31 George Strakosch and Robert Caporale, Vertical Transportation Handbook, 4th Edition (John Wiley \& Sons, 2010), 402.

32 Carporle, 402-403. 


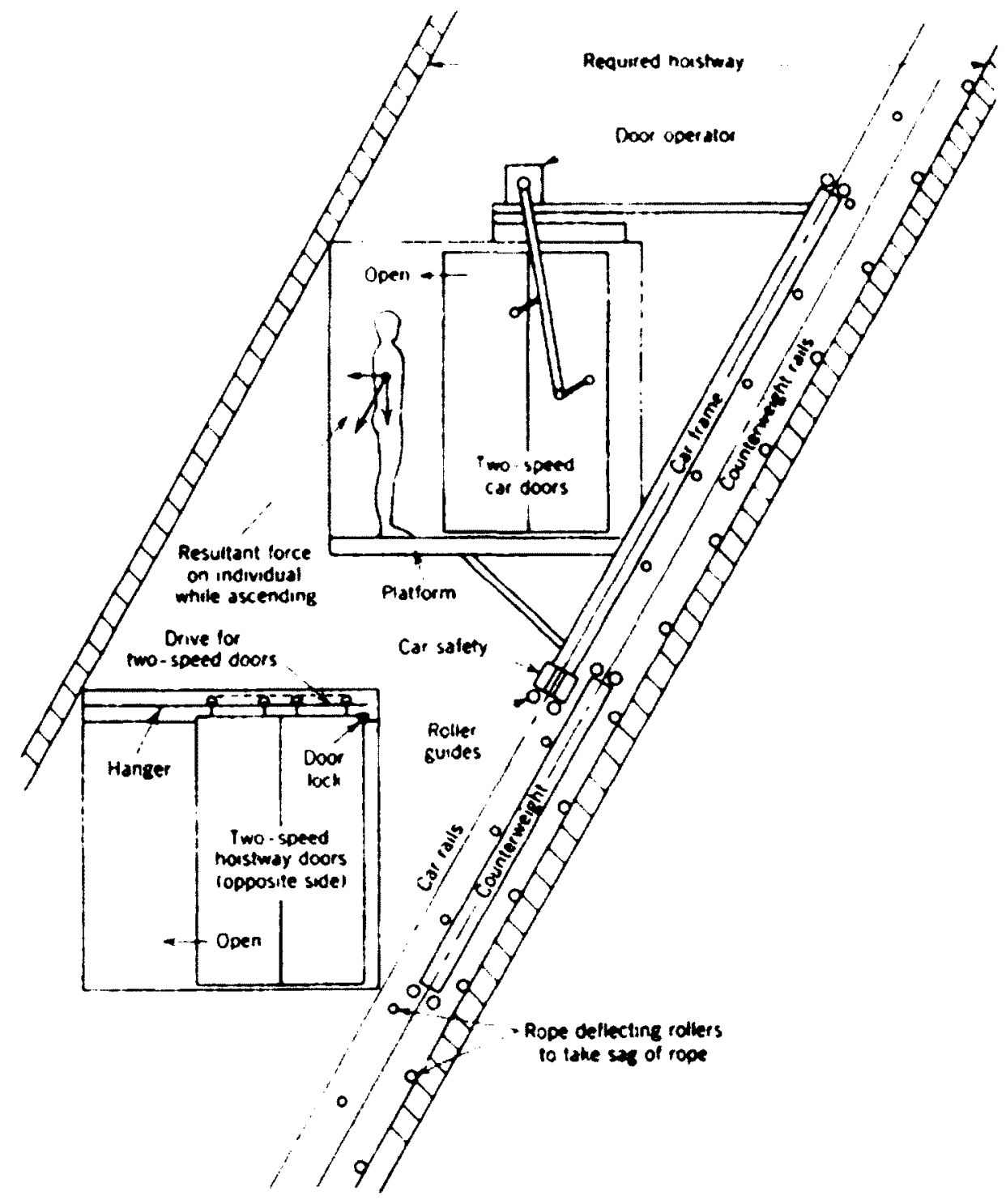

FIGURE 34:

ILLUUSTRATION OF LUXOR HOTEL'S ELEVATOR SHAFT AND ITS MECHANICAL WORKINGS 

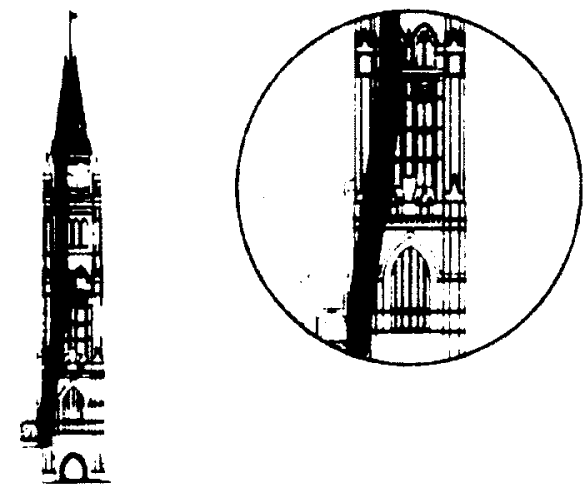

FIGURE 35:

DIAGRAM OF PEACE TOWER SHOWNG LOCATION OF THE ELEVATOR WITH A COMBINATION OF INCLINED AND VERTICAL RUNS

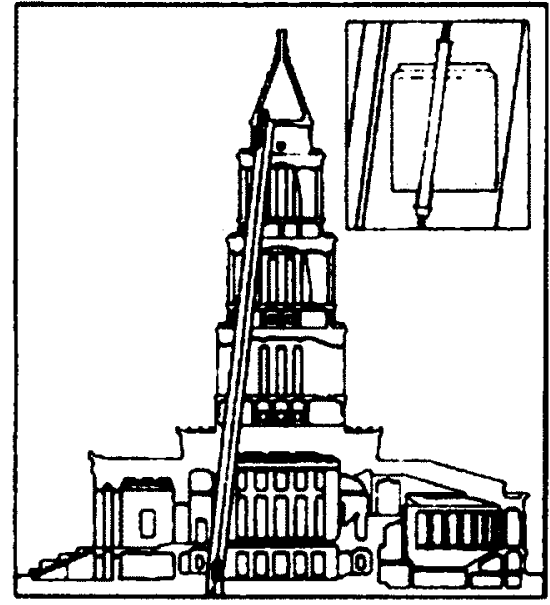

FIGURE 36 :

DIAGRAM OF MASONIC MONUMENT WITH A MULTI-PLANE ELEVATOR SYSTEM
The Luxor Hotel is shaped in a square pyramid form. There are four elevator cores located on the perimeter of the building, four of them on each corner making a total of 16 elevators. Inclined elevators by definition "travel a single inclined direction in a single plane. ${ }^{.33}$ Elevators that travel on multiple angles in the same plane can also be done. The Peace Tower of the Parliament building in Ottawa, Canada and the Eiffel Tower in Paris, France are of such examples. Elevators with multiple planes could also be realized such as the one installed in the Washington Masonic Monument in Alexandria, Virginia. ${ }^{34}$ Although designing the mechanical system to properly hoist the elevator cabs is a difficult engineering task, the research shown suggests that it is possible to achieve. The idea for multiple planes elevator will be further explained in the portfolio by connecting multiple elevator shafts to create an unconventional structural core. 


\section{Portfolio}

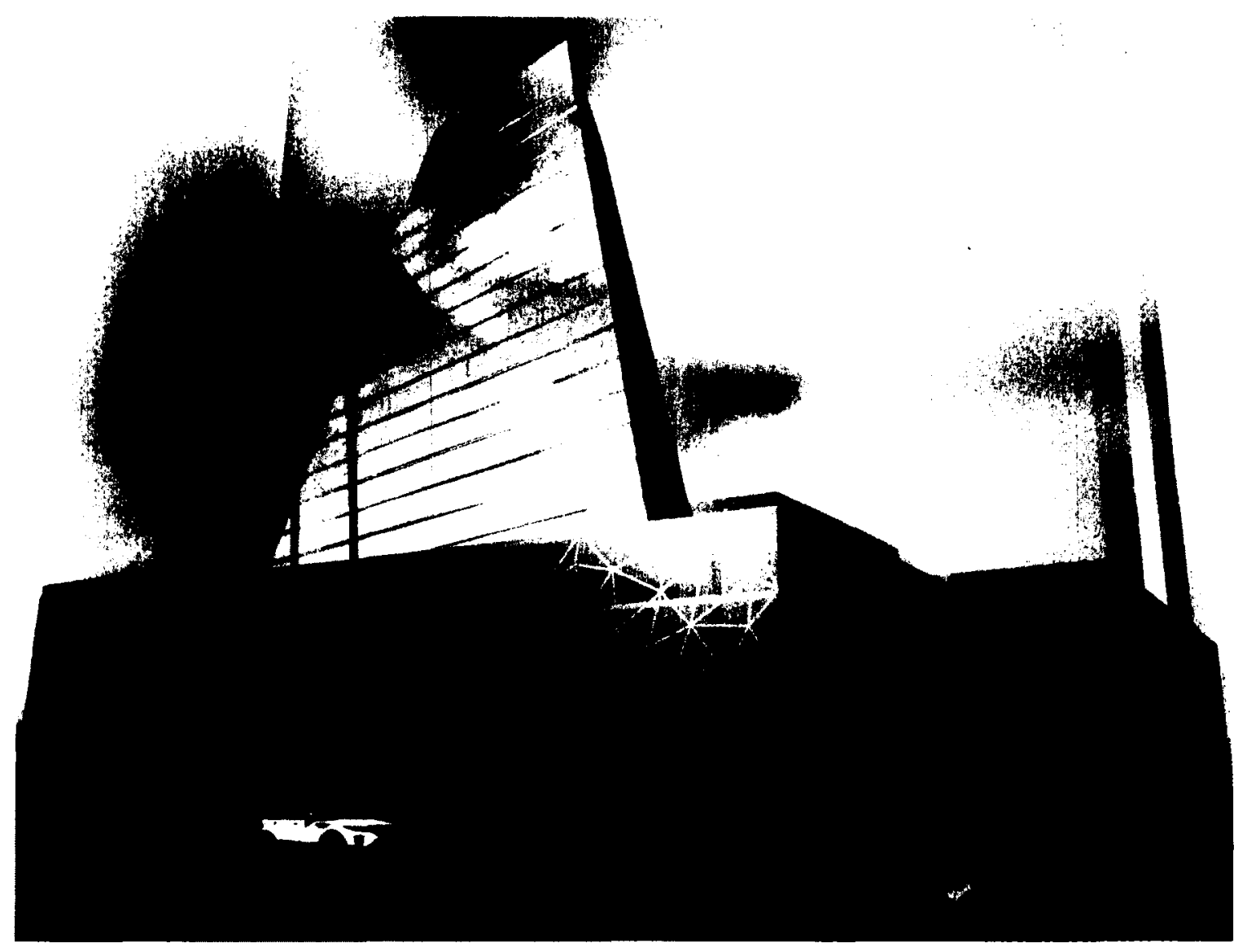

FIGURE 37:

EXTERIOR VIEW OF PROPOSED HOTEL 


\section{Project Brief}

The purpose of the portfolio is to develop an extended-stay hotel for the Creative Class in a richly cultured location with three main architectural objectives as discussed in previous sections: i. Encourage visitors to explore the building (create an unconventional environment that captivates their minds)

ii. Encourage interaction between people in public spaces (for psychological and spiritual needs)

iii. Create an easy storage/transport solution for personal belongings (for practical purposes and gives an opportunity for guests to customize their settings) 


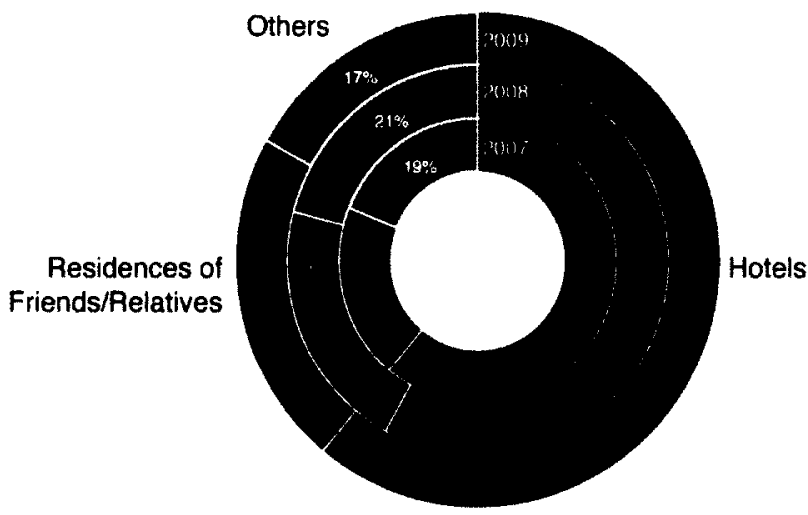

FIGURE 38 : TYPES OF ACCOMODATION VISITORS STAY IN

The site chosen is located in downtown Singapore, a South-East Asia country that has only $697 \mathrm{~km} 2$ of land. Although its country is small in footprint, it has a population of 5.3 Million and officially celebrates four major cultures through its multicultural diversities. ${ }^{35}$ Singapore ranks as one of the top countries in Florida's Creative Index ${ }^{36}$ with a strong economy that has subsidiary offices of global companies located there which makes it a very reasonable location for the Creative Class to travel there for business trips. Singaporeans have backgrounds from the Chinese, the

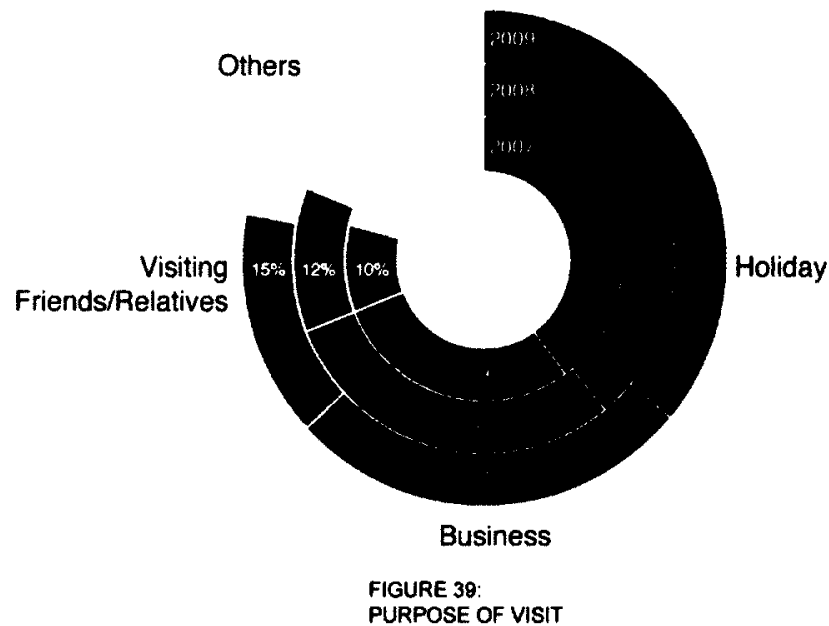

Philippines, the Malaysian and the Indonesian, with the majority of them speaking English as one of their official languages.

The unique mixtures of its traditions, the stability of the government and strict legal policies make it one of the best places to travel to for an easy transition into the world of the East. Thus, it could be a place for the Creative Class to seek various eastern customs and values without venturing to several parts of Asia.

35 Central Intelligence Agency, CIA - The World Factbook, 15 Dec 2012 <https://www.cia.gov/library/publications/the-world-factbook/geos/sn.html>. 36 Florida, 278. 


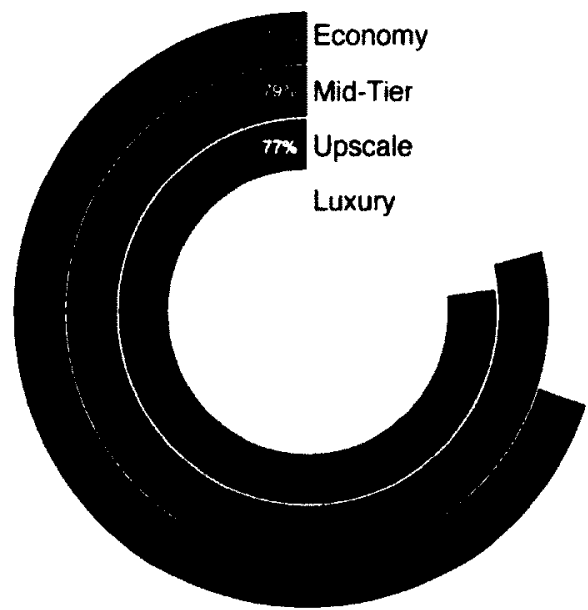

FIGURE 40:

AVERAGE OCCUPANCY RATE BY TIER (2009)

Statistics from the Singapore Annu-

al Report on Tourism 2009 showed that around 180,000 of the 9.7 million people that visit the country that year stayed for more than 30 days. ${ }^{37}$ It also showed that roughly $60 \%$ of the visitors stayed in hotels and kept these accommodations to up to at least $70 \%$ occupancy rate in all price ranges. These numbers alone support the proposal for an extended-stay hotel. The site is conveniently located in the downtown core and is within walking distances to some of the most popular attractions in the country.

The site currently sits vacant and is directly across one of most popular food courts for locals and tourists alike. The octagonal shaped building houses many culinary dishes with recipes from different cultures. The site is also conveniently blocks away from Marina Bay with stunning views of the city's inner skyline. Although mainly office buildings surround the immediate site, the location is desirable for the Creative Class who wants to live close to their workplace with easy access to the subway system just two blocks away.

37 Singapore Tourism Board, Annual Report on Tourism Statistics 2009, Annual Report (Singapore: YourSingapore, 2010), 22. 


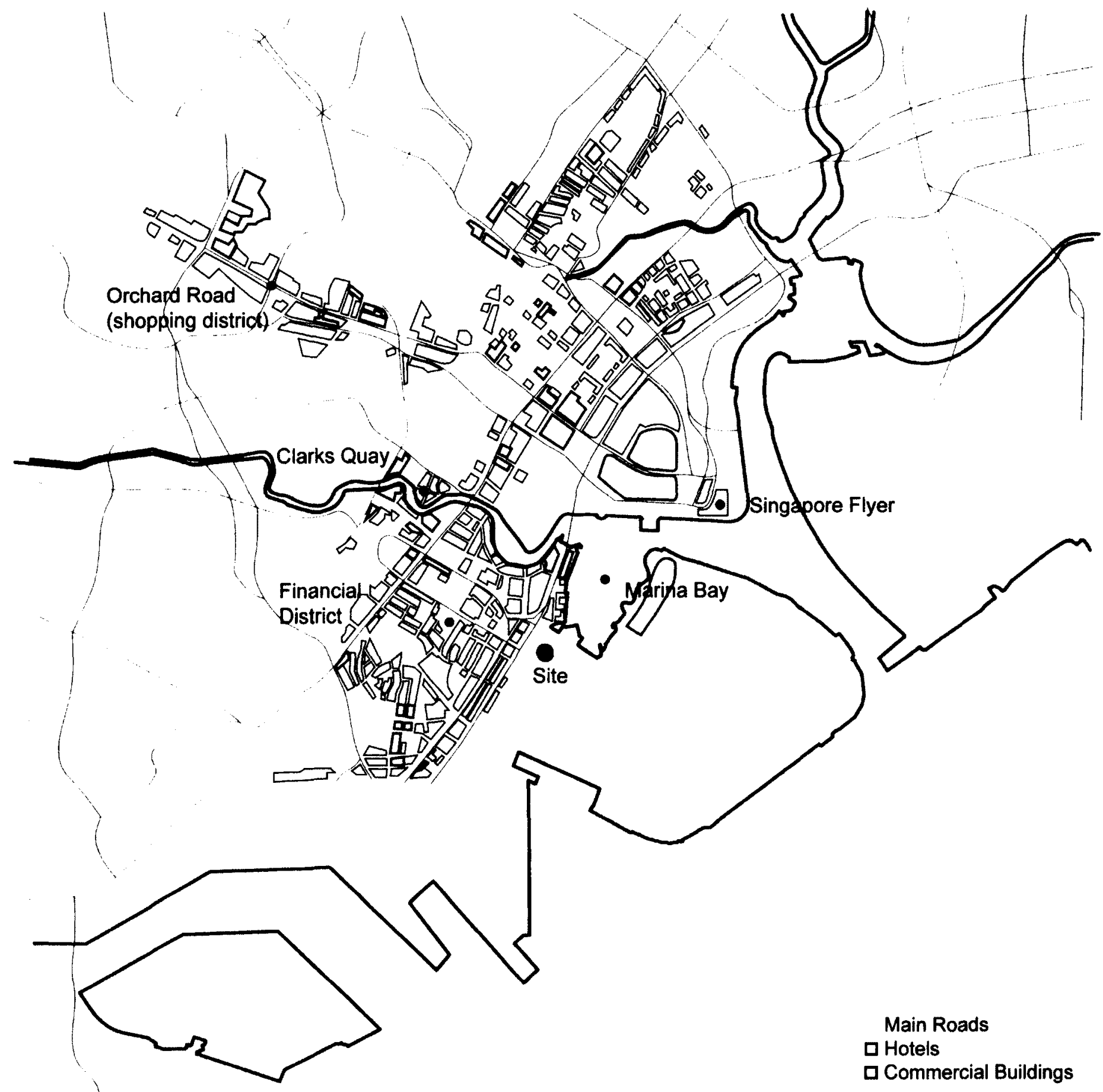

FIGURE 41

SITE ANALYSIS WTH MAP SHOWNG COMMERCLAL AND HOTEL BUILDINGS NEAR BY 

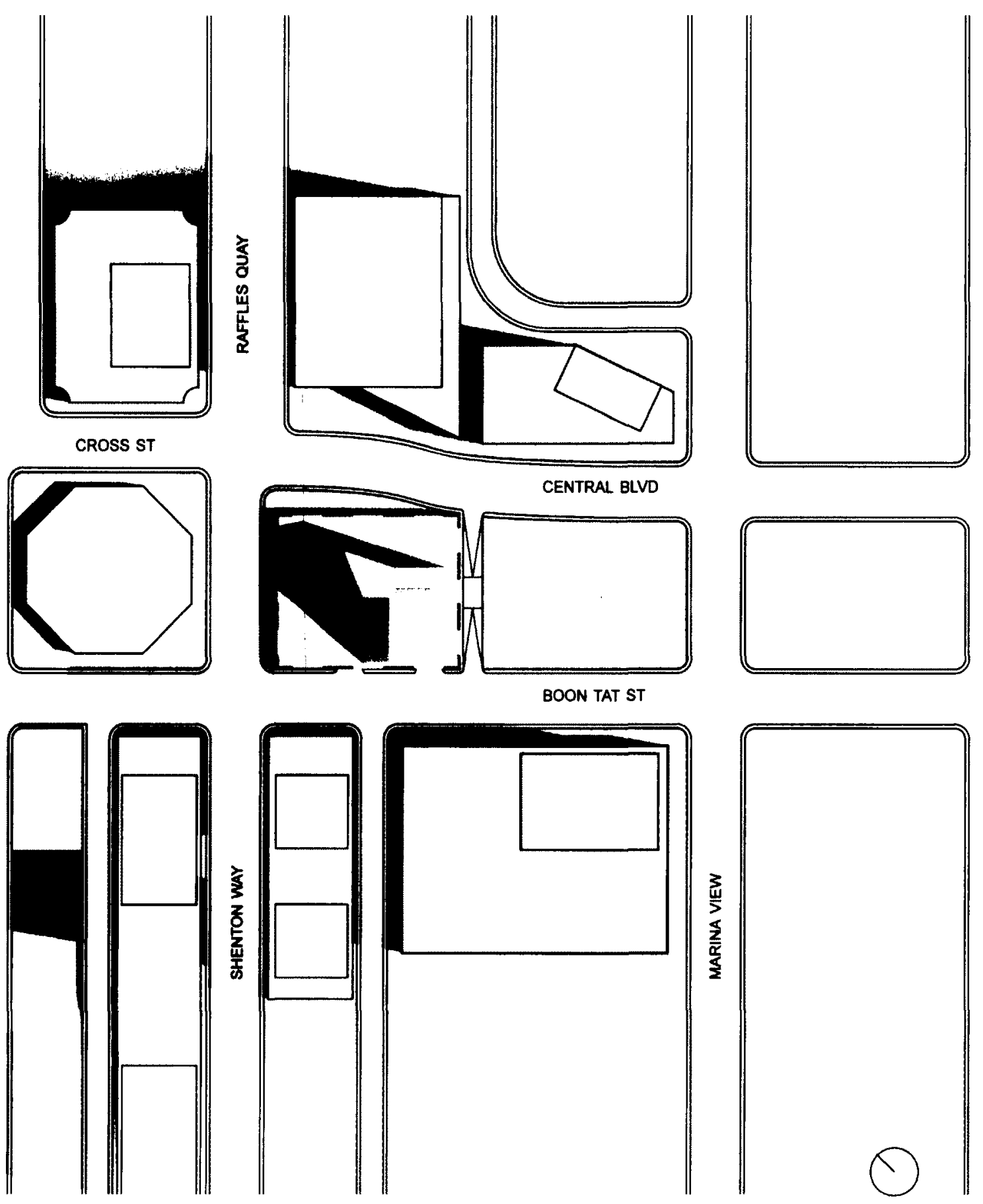

FIGURE 42

SITE MAP WTTH SHADOW DEPICTING THE PROPOSED HOTEL

BEING NESTLED IN A SEA OF COMMERCIAL SKYSCRAPERS 


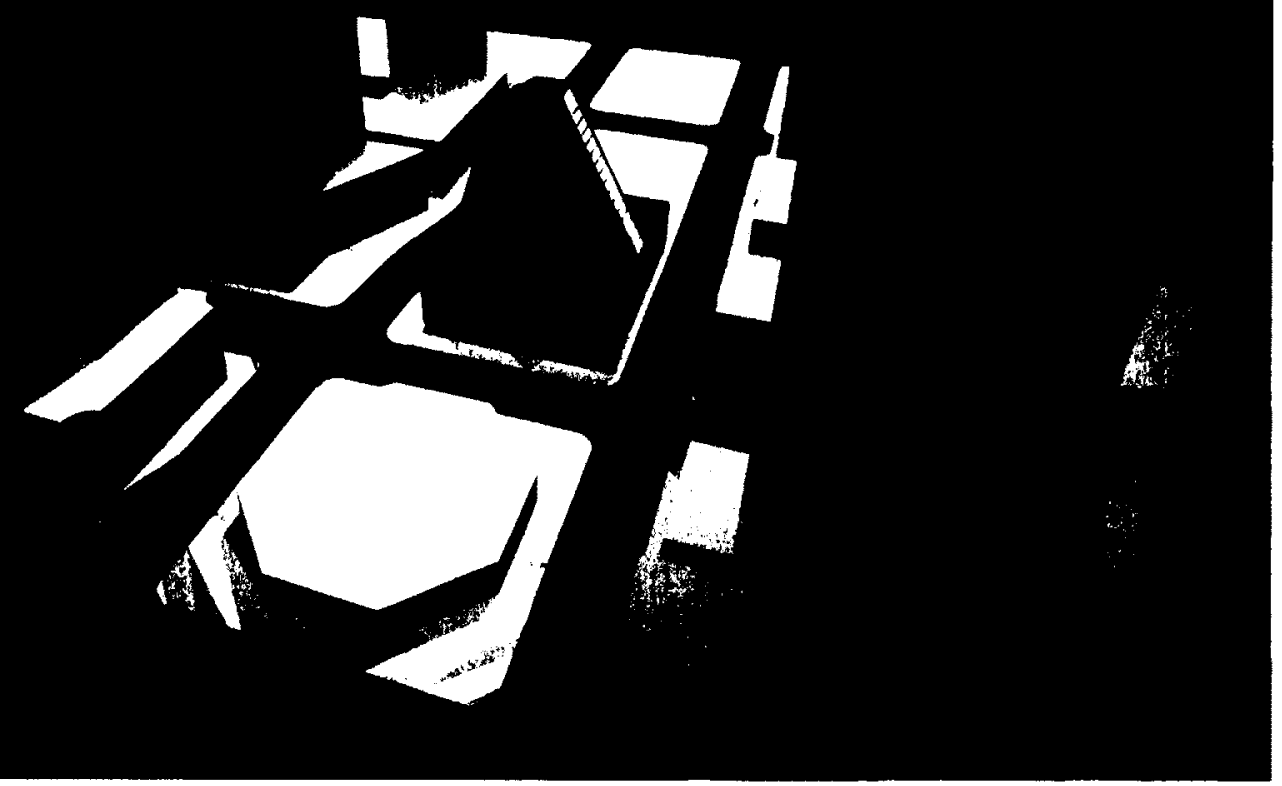

FIGURE 43:

NORTHWEST AERIAL VIEW WITH MASSING OF BUILDINGS IN THE IMMEDIATE VICINITY 


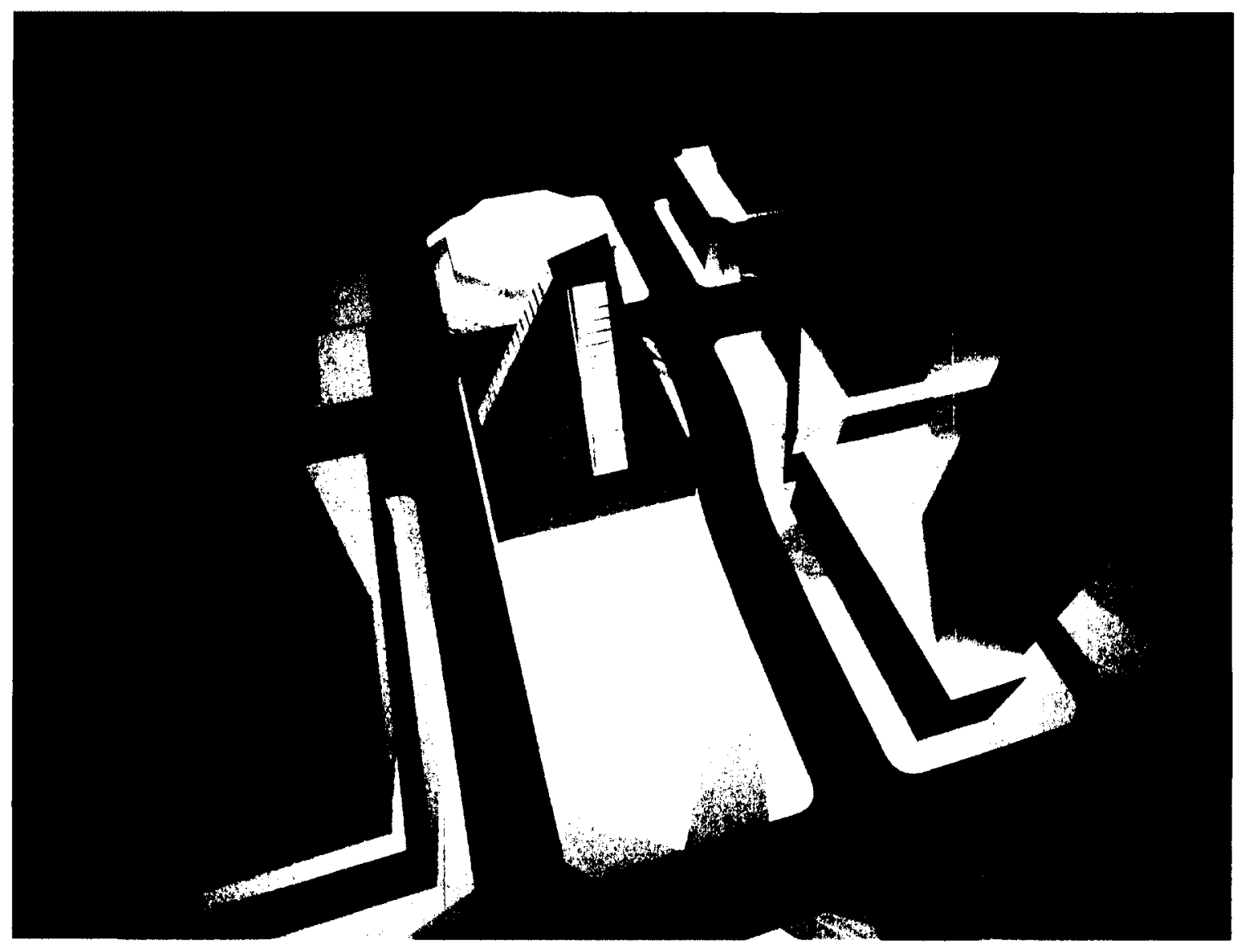

FIGURE 44:

SOUTHEAST AERIAL VIEW WITH MASSING OF BUILDINGS IN THE IMMEDIATE VICINITY 
Architectural Implication targeting the first objective with structural innovation:

The main goal for the project is to create an architecture that facilitates moments of surprises, no matter how many times the user had visited the building before. The design approach to this is to rethink the way we treat the structural 'core' and to open up opportunities that challenge the user to explore the building in public spaces.

In conventional buildings, many high rises such as office buildings or hotel towers use the elevator shafts as its 'structural core'. By using this technique, every floor plate remains relatively the same and the location of where one is within a building is predictable. However, if the position of the elevator location on each floor is different from floor to floor, then visitors experience a multiplicity of circulation routes when they move through the building. The diagram shown in Figure indicates the location of the elevators in a superimposed axo-

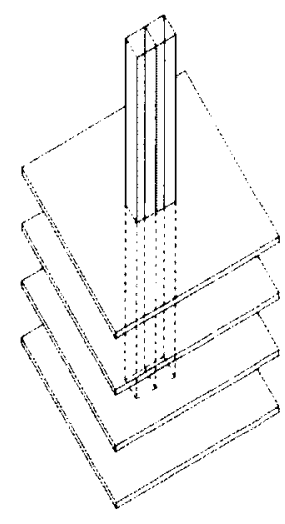

$$
\begin{aligned}
& \text { FIGURE 45: } \\
& \text { DIAGRAM OF CONVENTIONAL } \\
& \text { BUILDING CORE }
\end{aligned}
$$

nometric view. If we shift these elevator locations to the desired level as shown in Figure and create a diagonal elevator shaft connecting them all together. Effectively, the elevator shafts as a whole, created an even stronger 'structural core' since it have been reinforced by a diagrid-like structure. Even without the presence of any floor slabs, this 'Diagrid Core' (Figure) can theoretically be stable enough to stand on its own because it is in an enclosed loop with at least 3 
FIGURE 46 :

SUPERIMPOSED AXONOMETRIC VIEW OF ELEVATOR LOCATION ON ONE FLOOR PLATE

FIGURE 47

VERTICALLY MANIPULATING THE ELEVATOR LOCATION TO VARIOUS

LEVELS

FIGURE 48

CONNECTING MULTI-LEVELED

ELEVATOR LOCATION TO CREATEA

NEW BUILDING CORE

(THE OLAGRID CORE)

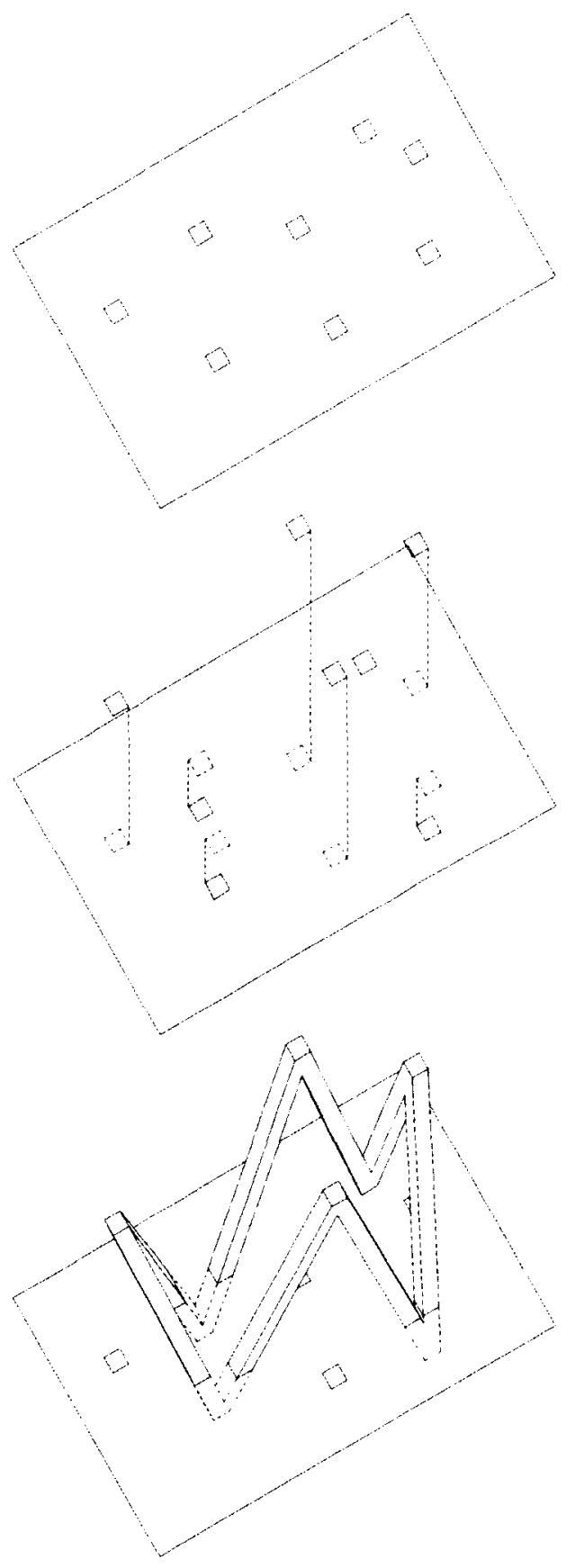


points of contact for its foundation. The void created within this Diagrid Core can now act as the atrium space where it offers people a dramatically different experience compared to other atriums they have been in and serves at a reference point for orientation purposes.

The triangular skylight that opens up the atrium allows direct sunlight into the building. The triangular patterned mullions cast a shadow of patterns on the lobby ground and assists in animating the inside of the building through the day.

The construction of the Diagrid Core/ Elevator shaft will be constructed out of steel frame and will be welded to steel beams at every floor. Then topped with conventional steel trusses, metal decking and poured concrete. By con- structing the Diagrid Core out of steel frame, glass could be applied for its enclosure and allows passengers riding the elevators to look out at every floor to get a sense of the activities happening around them. The Diagrid Core glass enclosure will shimmer from within the building like a sculptural piece with metallic window film applied to it. When approaching the building from afar, the transparent façades and the jewel like effect of the Diagrid Core enclosure resembles a museum glass box that exhibits the finest curated sculptural work at a large scale. The architectural implementation of the Diagrid Core effectively solves the first objective stated earlier as it produces an exciting journey for people exploring the building. 


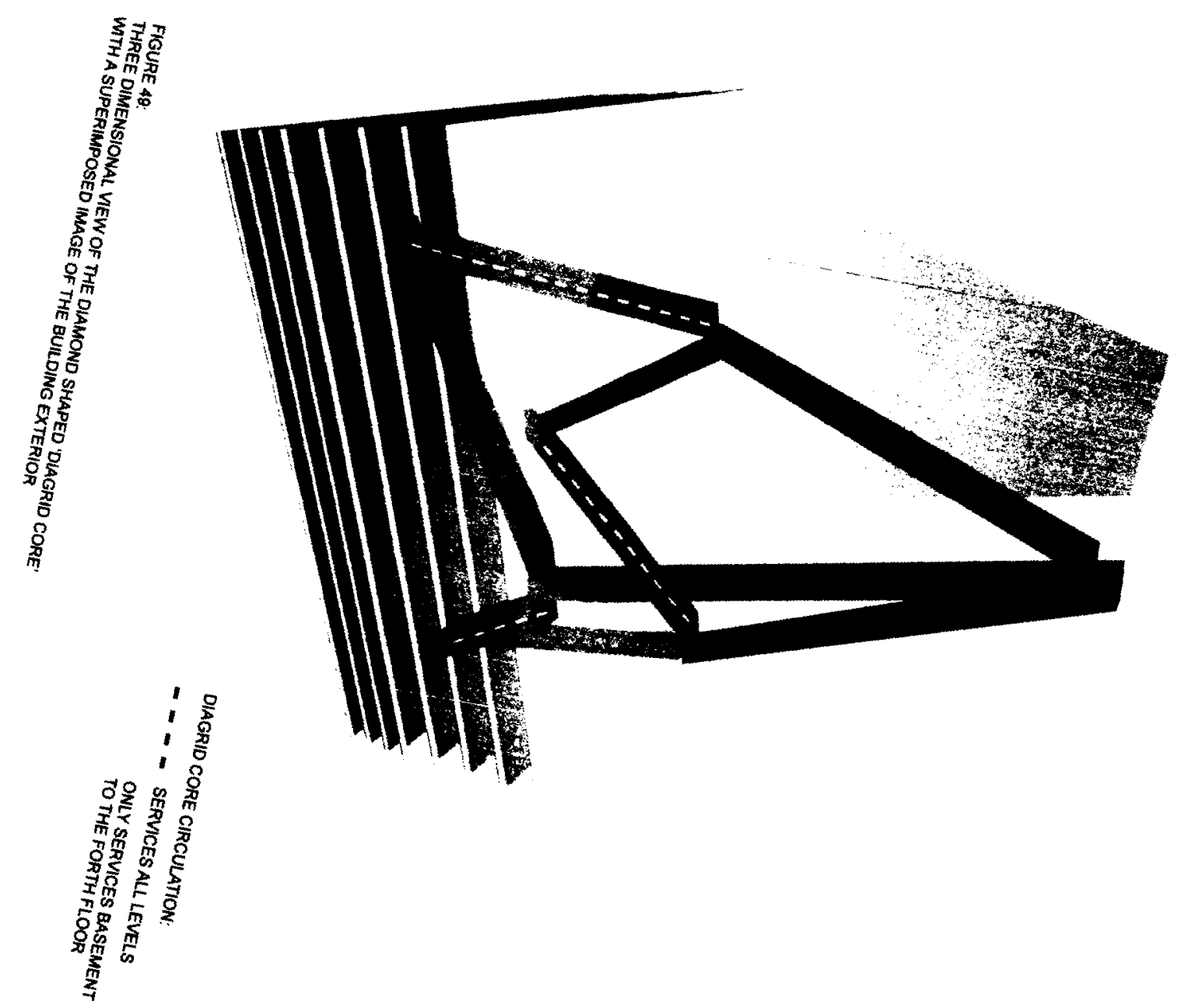




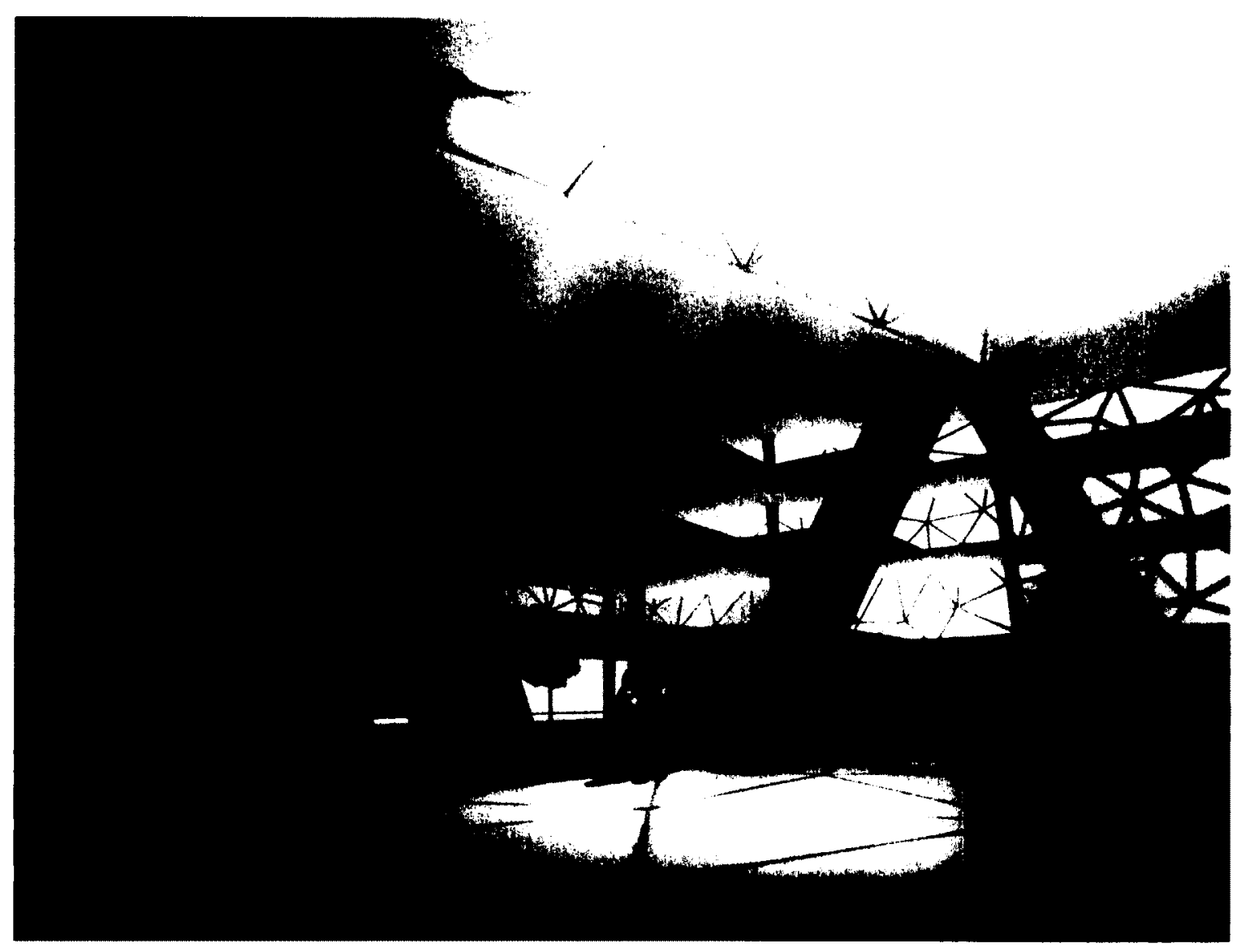

FIGURE 50:

LOBBY INTERIOR VIEW OF THE ATRIUM SPACE 


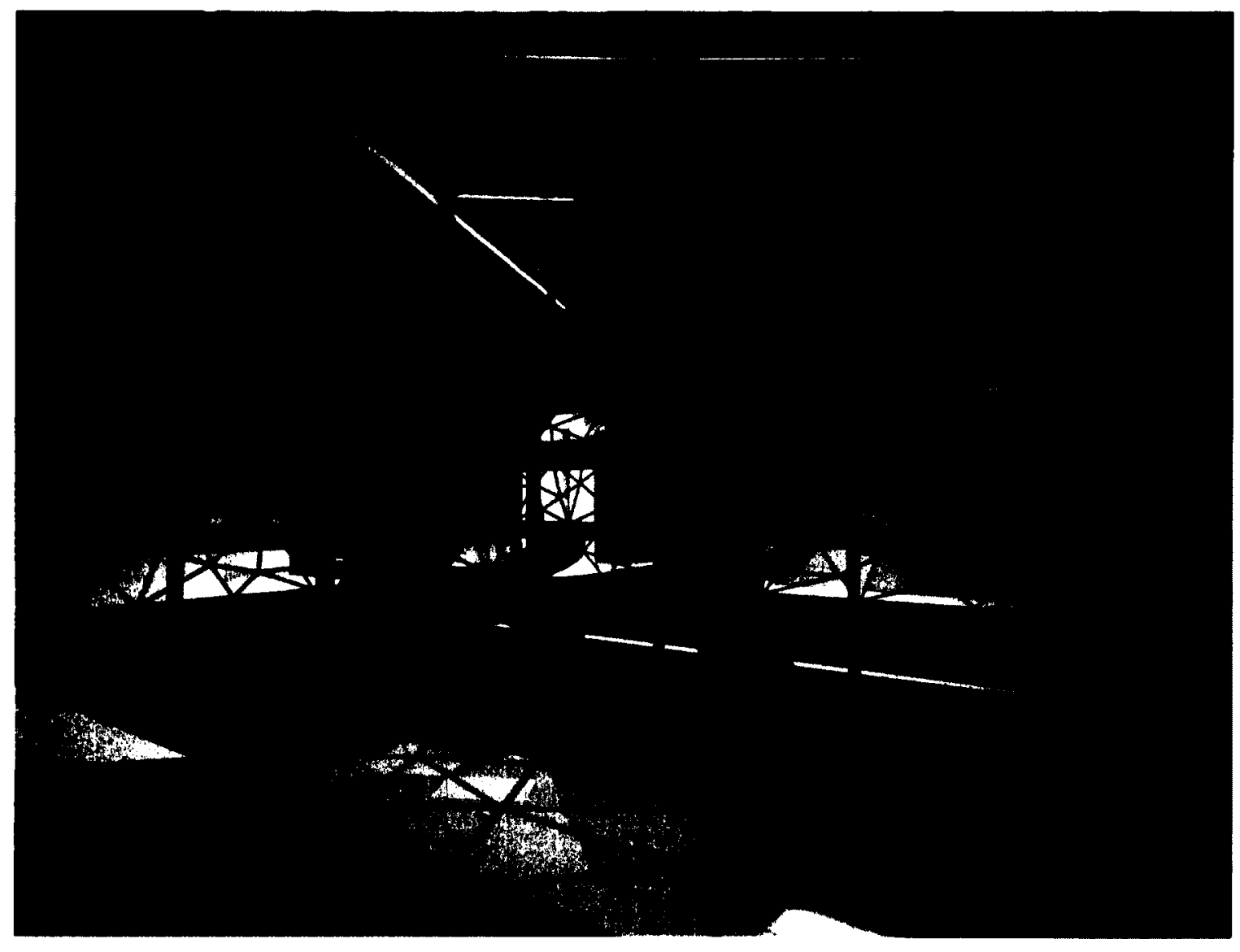

FIGURE 51:

VIEW FROM ONE OF THE ELEVATOR SHAFTS LOOKING INWAROS TO THE ATRIUM 


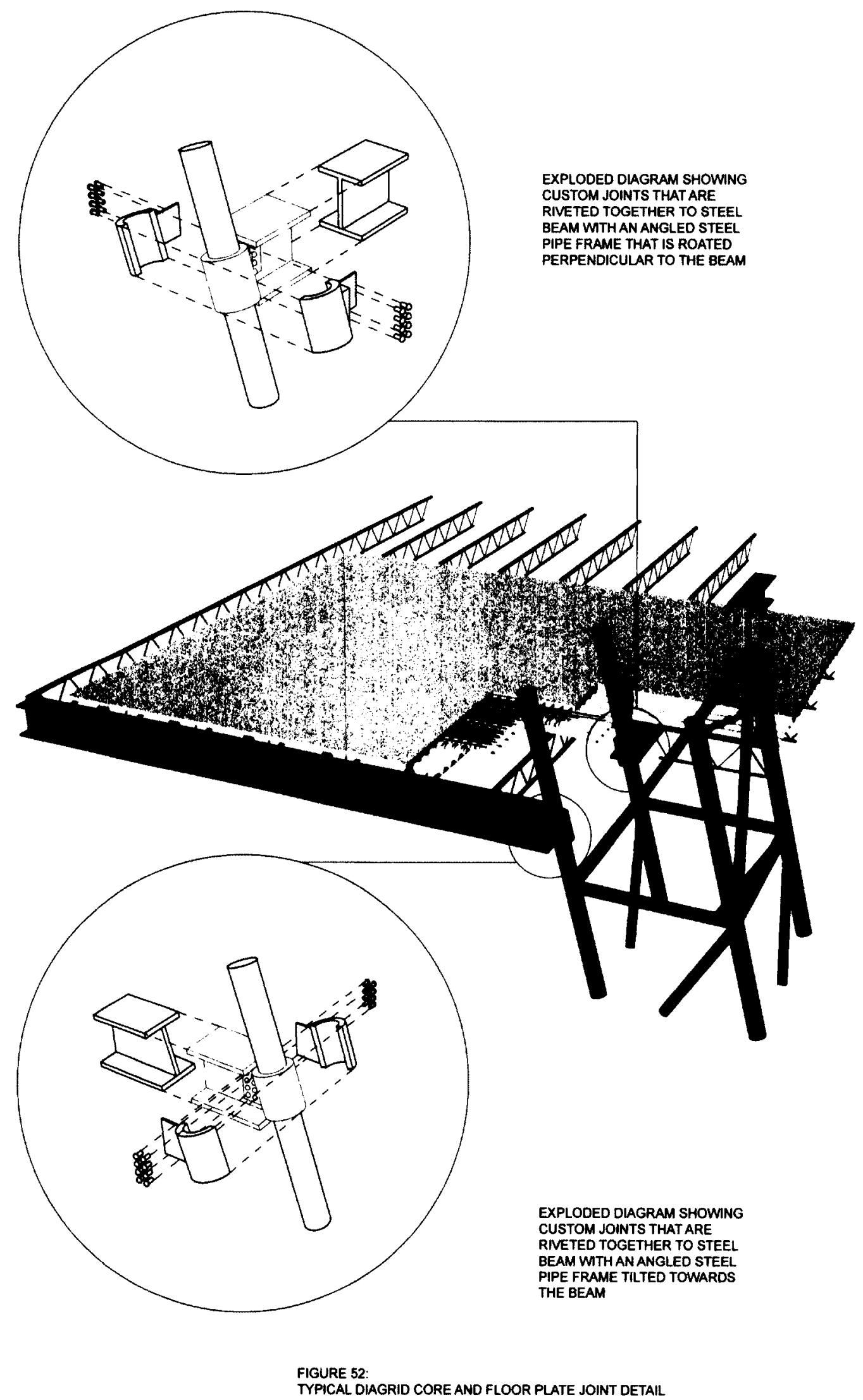




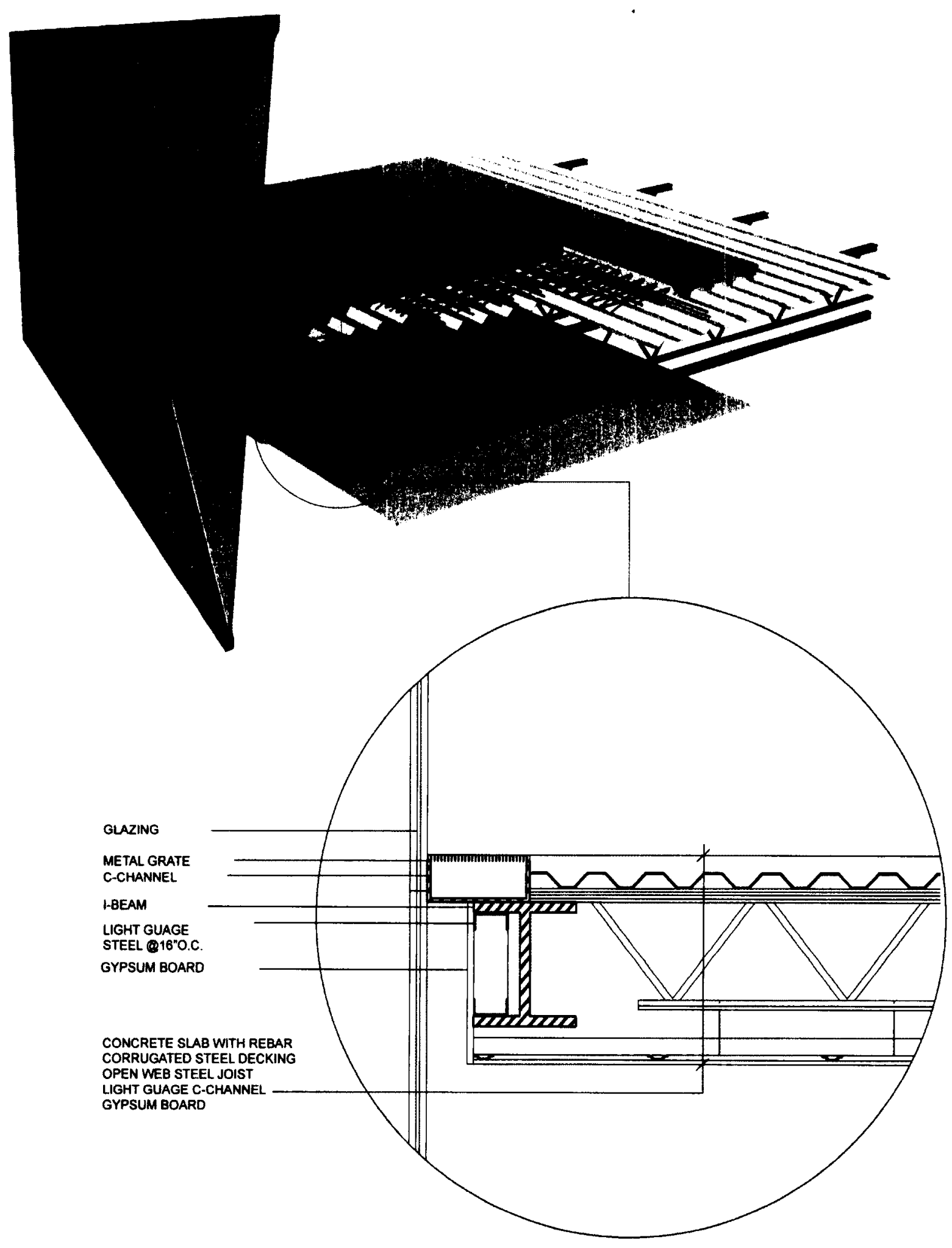

FIGURE 53:

TYPICAL CURTAIN WALL FACADE AND FLOOR PLATE CONNECTION DETAIL. 


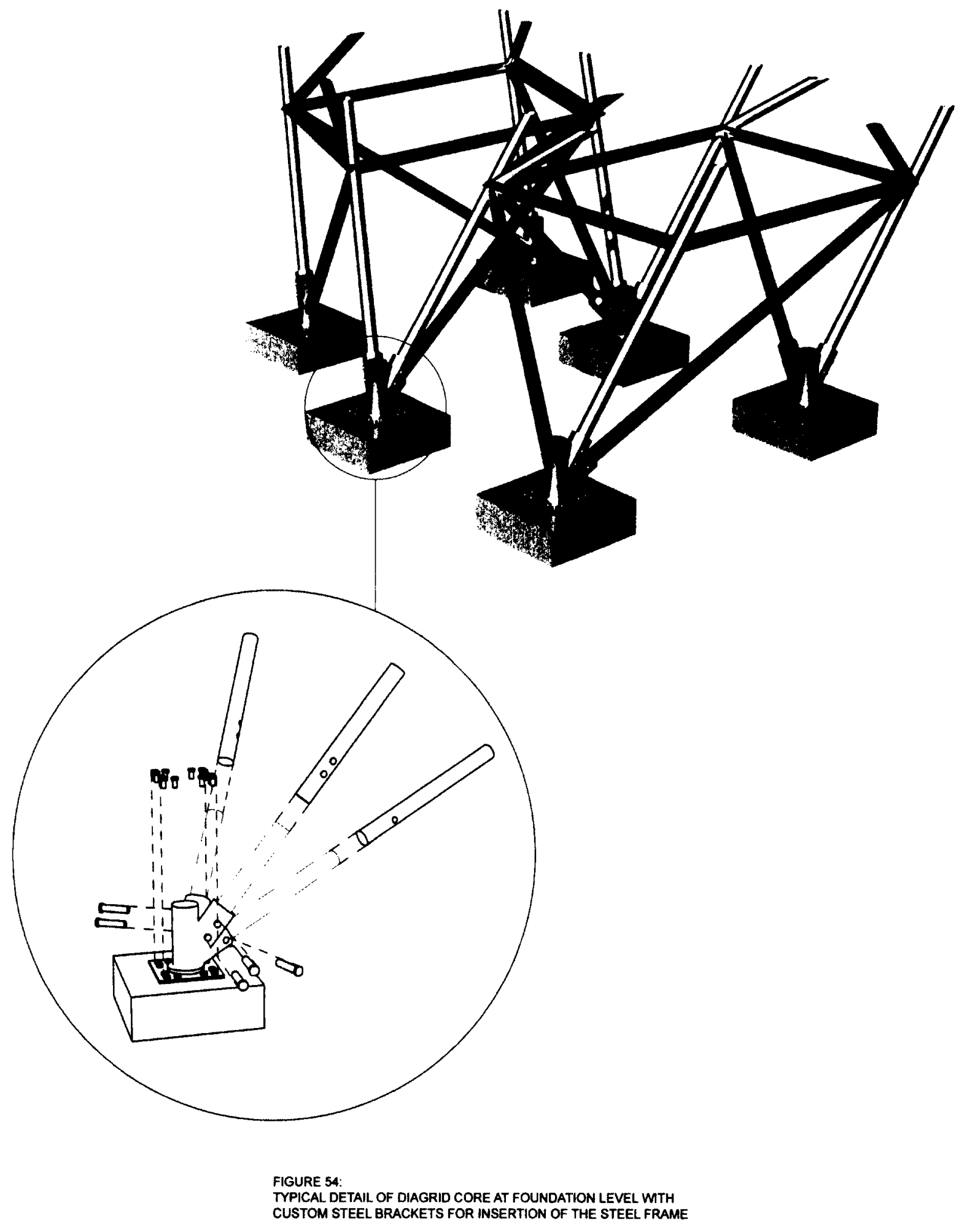


Architectural implication targeting the second objective with organization strategies:

The proposed building contains all the amenities required by the Creative Class, and typical of most traditional hotels. This includes restaurants and cafes on the second floor. Offices, meeting rooms with various sizes, a library, Internet lounge and working stations are located on the third floor. The spiral staircase along with the elevators provides accesses to these floors and welcomes the public to occupy these spaces. A swimming pool, fitness center, spa and salon are on the forth floor where primary access are by elevators to reserve the facilities for hotel guests or for clients with appointments. All of these amenity spaces have completely open concept floor plan, with the exception of isolated rooms or pods for privacy such as washroom, kitchen or private meeting spaces. The openness of the floor plans allows people to move freely from one space to another; this combined with the unconventional elevators could generate opportunities for people to collide and start impromptu discussions. 


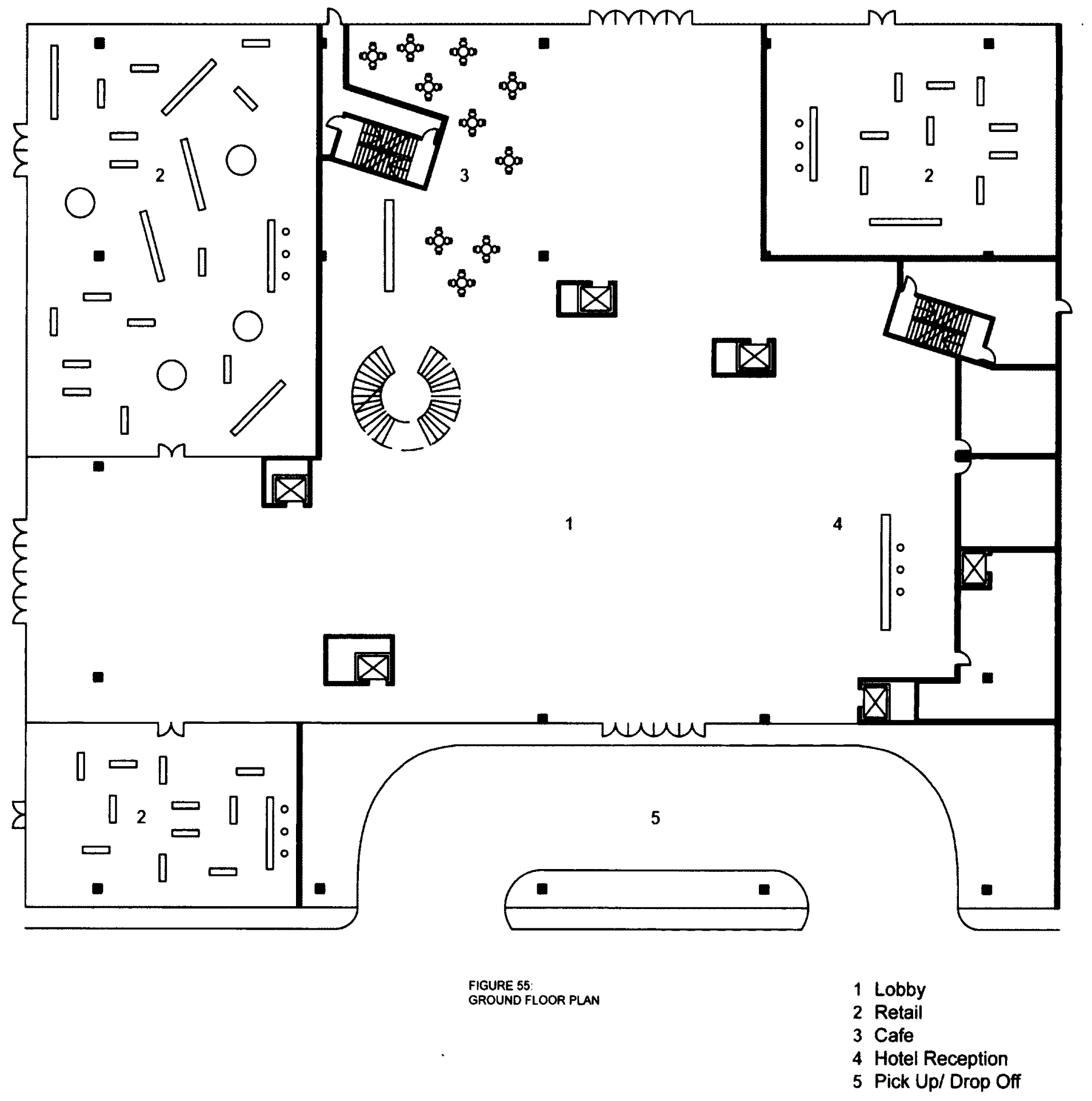




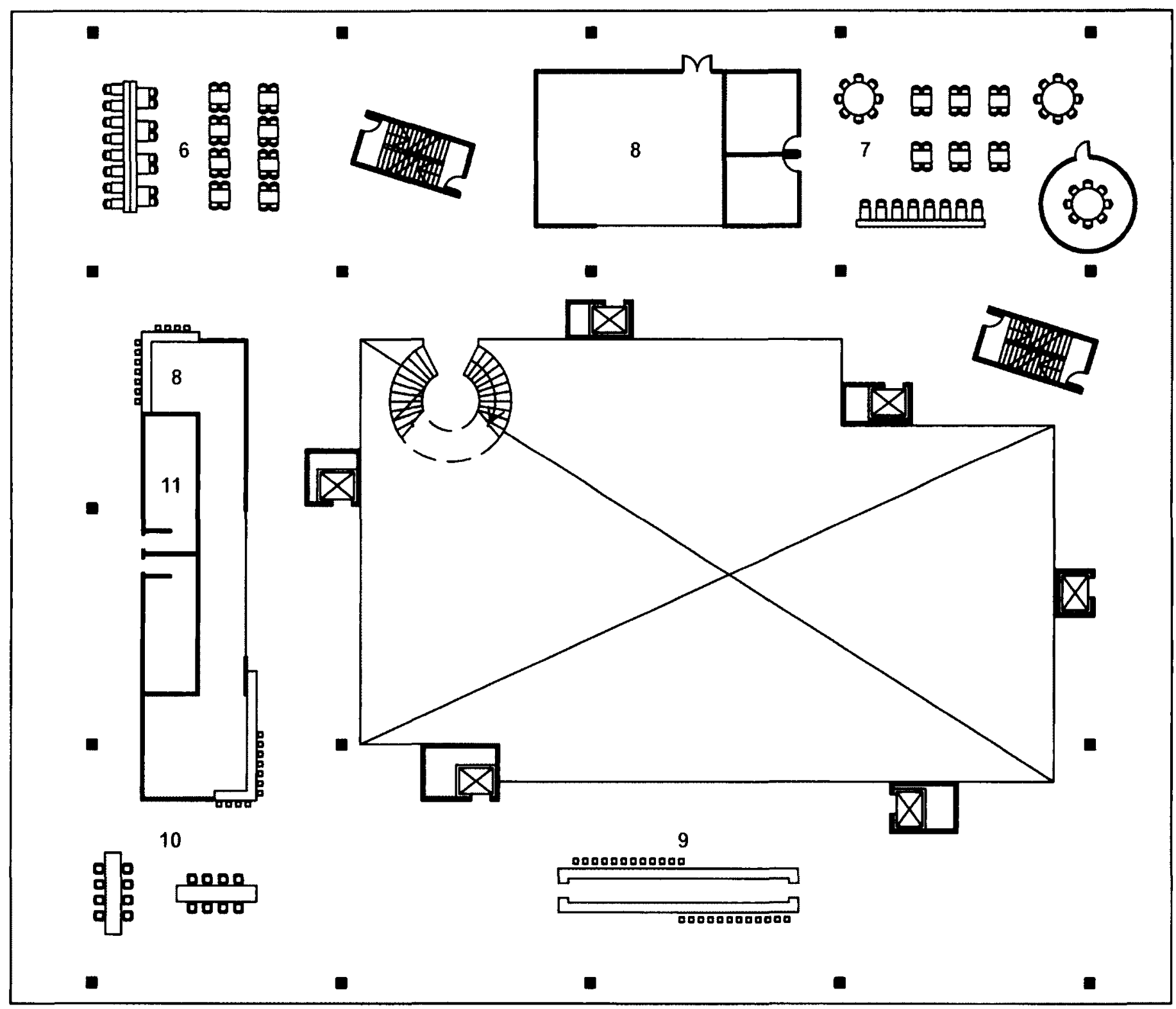

6 Restaurant A

7 Restaurant B

8 Kitchen

9 Bar

10 Private Dinning

$11 \mathrm{~W} / \mathrm{C}$ 


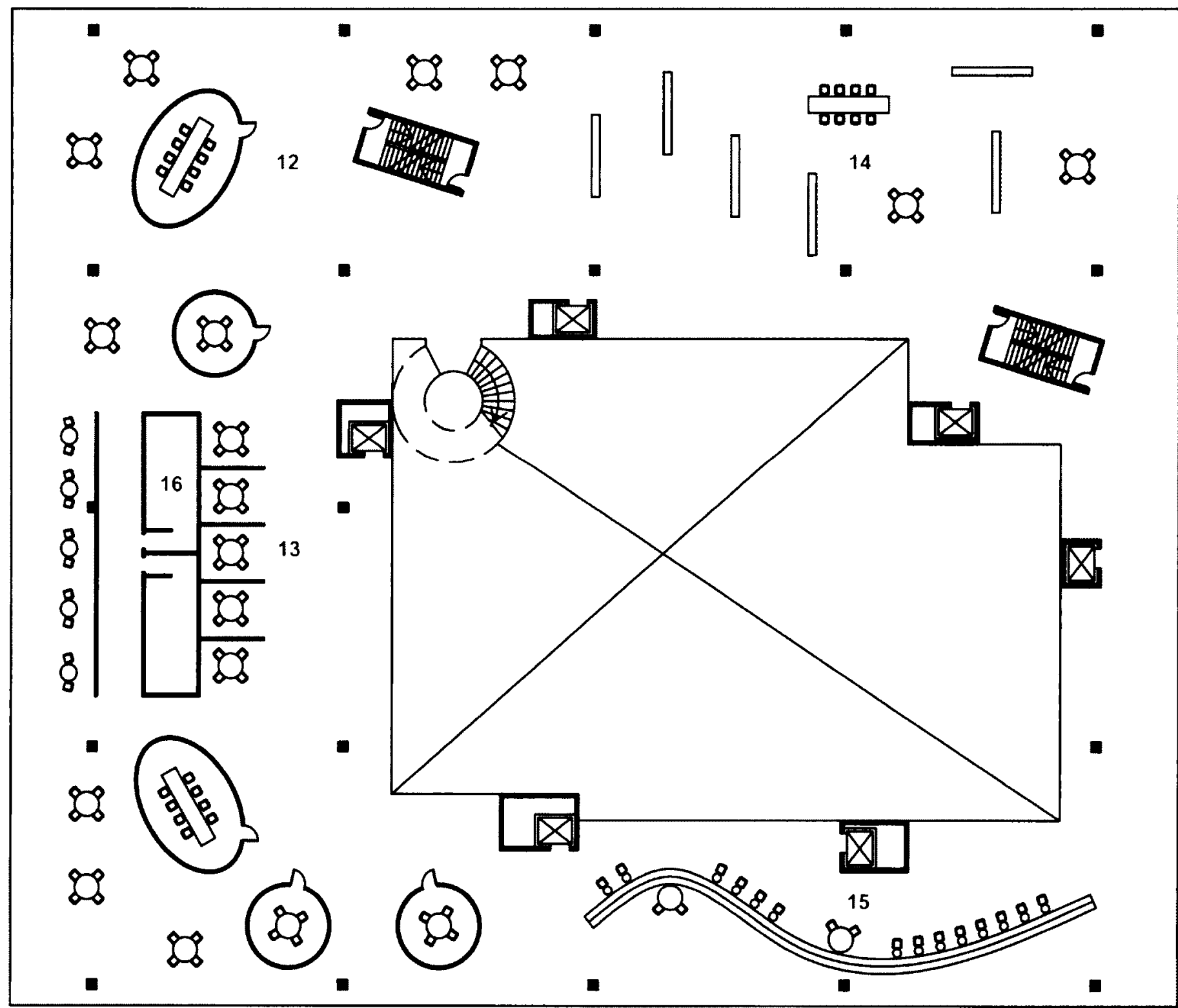

FIGURE 57

3RD LEVEL FLOOR PLAN

12 Meeting Rooms

13 Work Stations

14 Library

15 Internet Lounge

16 Washrooms 


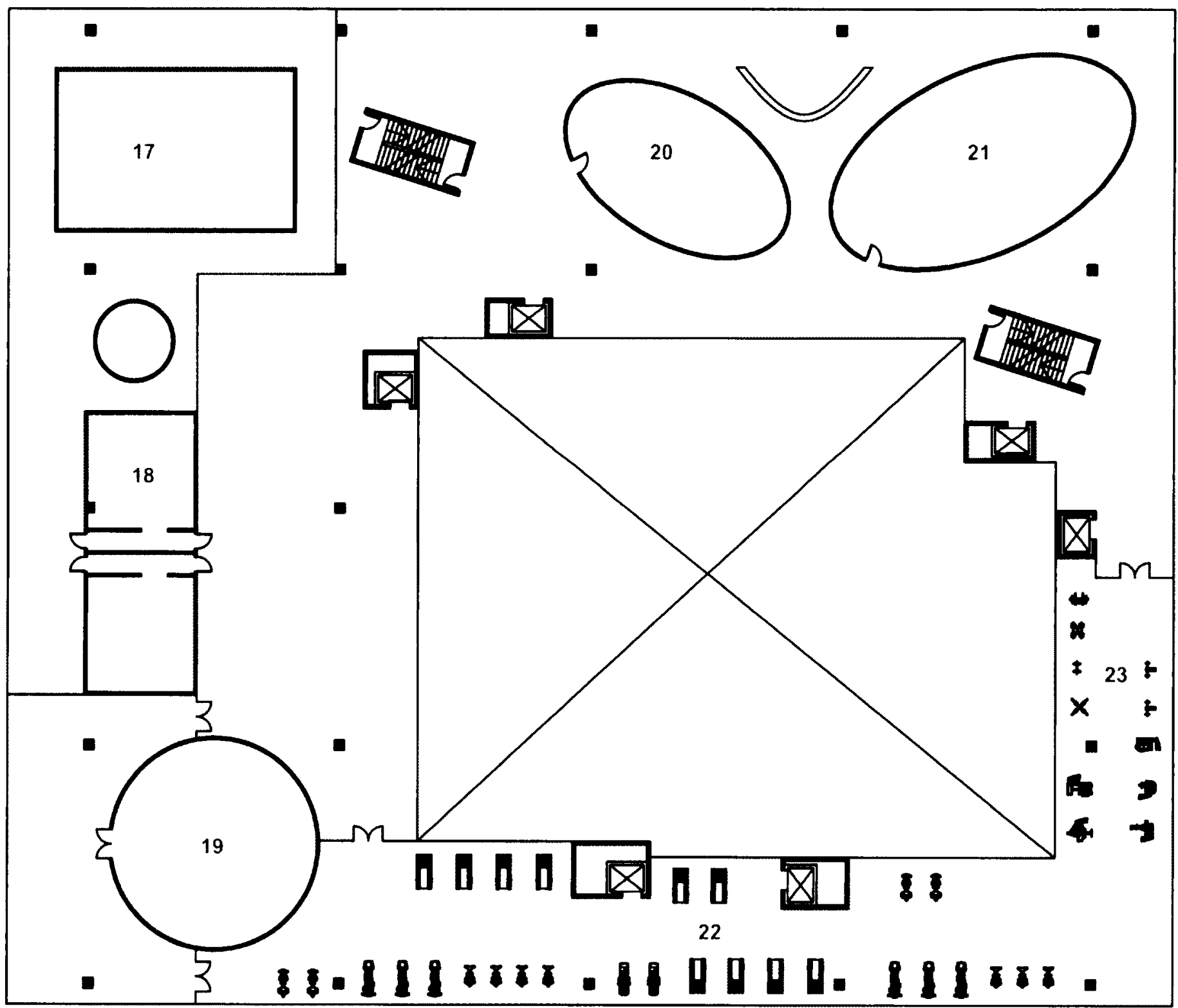

FIGURE 58

4TH LEVEL. FLOOR PLAN
17 Swimming Pool

18 Washrooms

19 Spa

20 Aerobics
21 Yoga

22 Cardio Room

23 Weight Room 


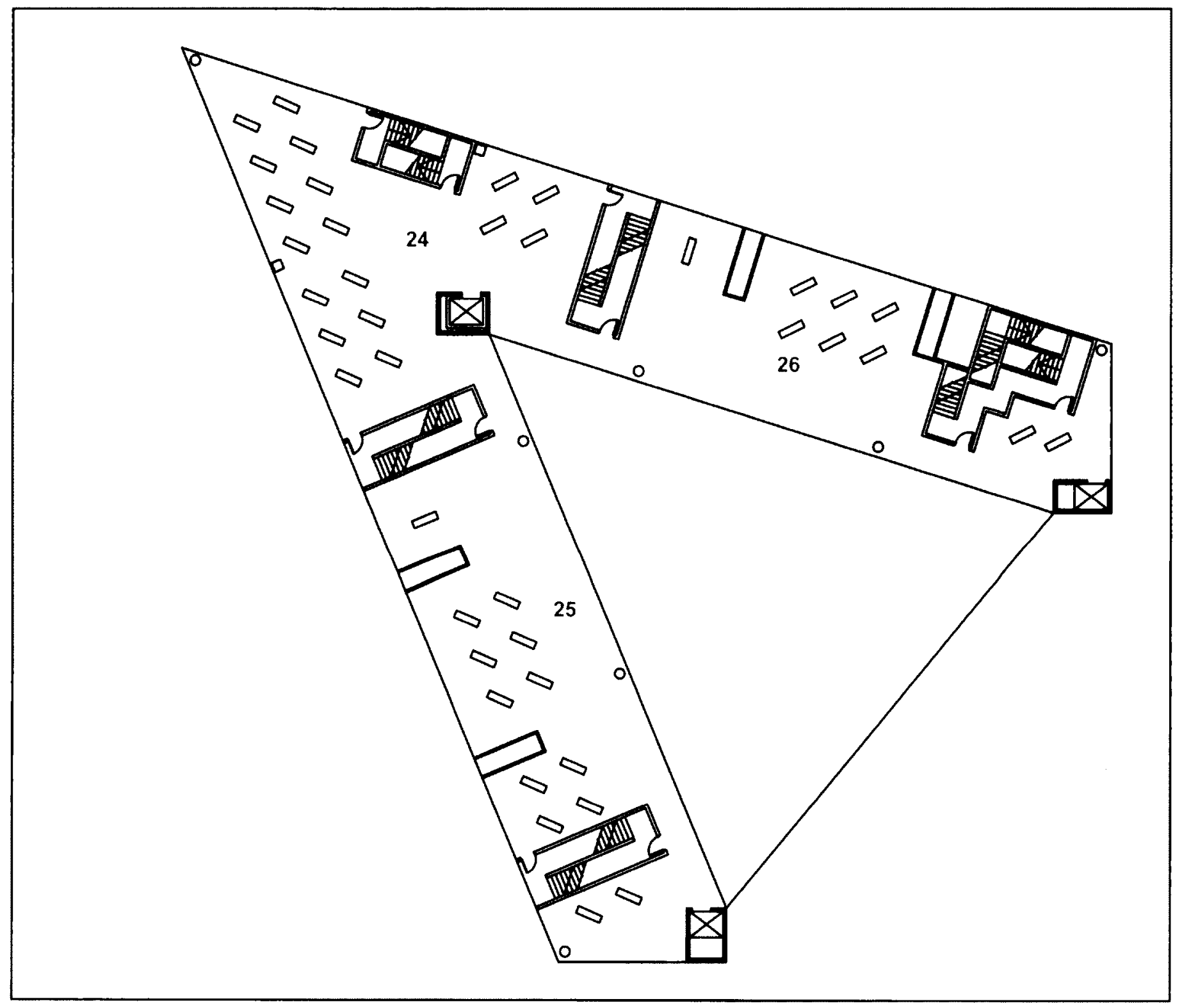

FIGURE 59:
5TH LEVEL FLOOR PLAN
24 Gallery

25 Permanent Colection

26 Temporary Collection 


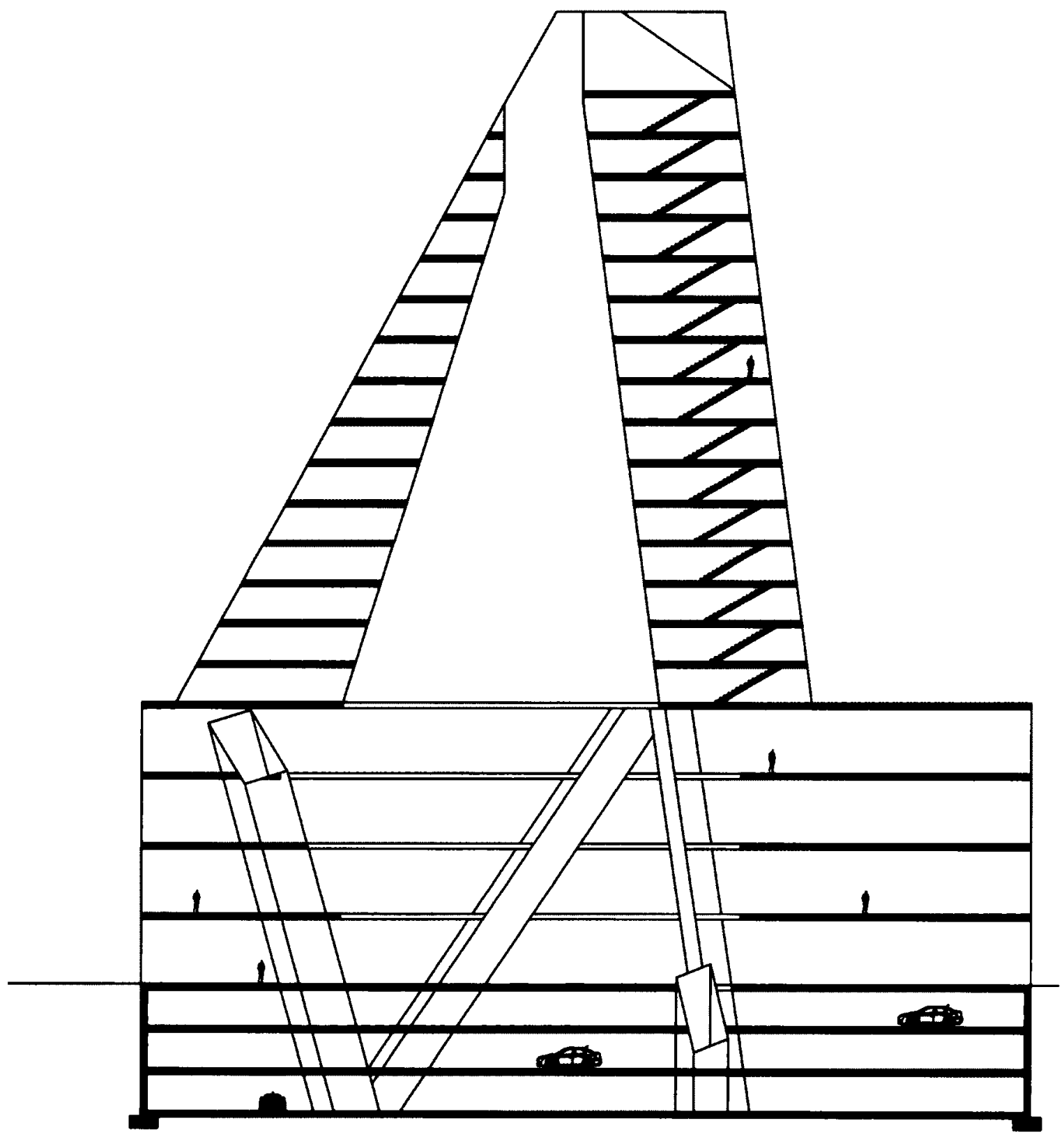

Hotel

Gallery

Fitness Club

Work Station

$\frac{\text { Library }}{\text { Bar }}$ Restaurants

Retail

Reception

FIGURE 60:

SECTION VIEW THROUGH BUILDING DEPICTING THE UNCONVENTIONAL CORE 


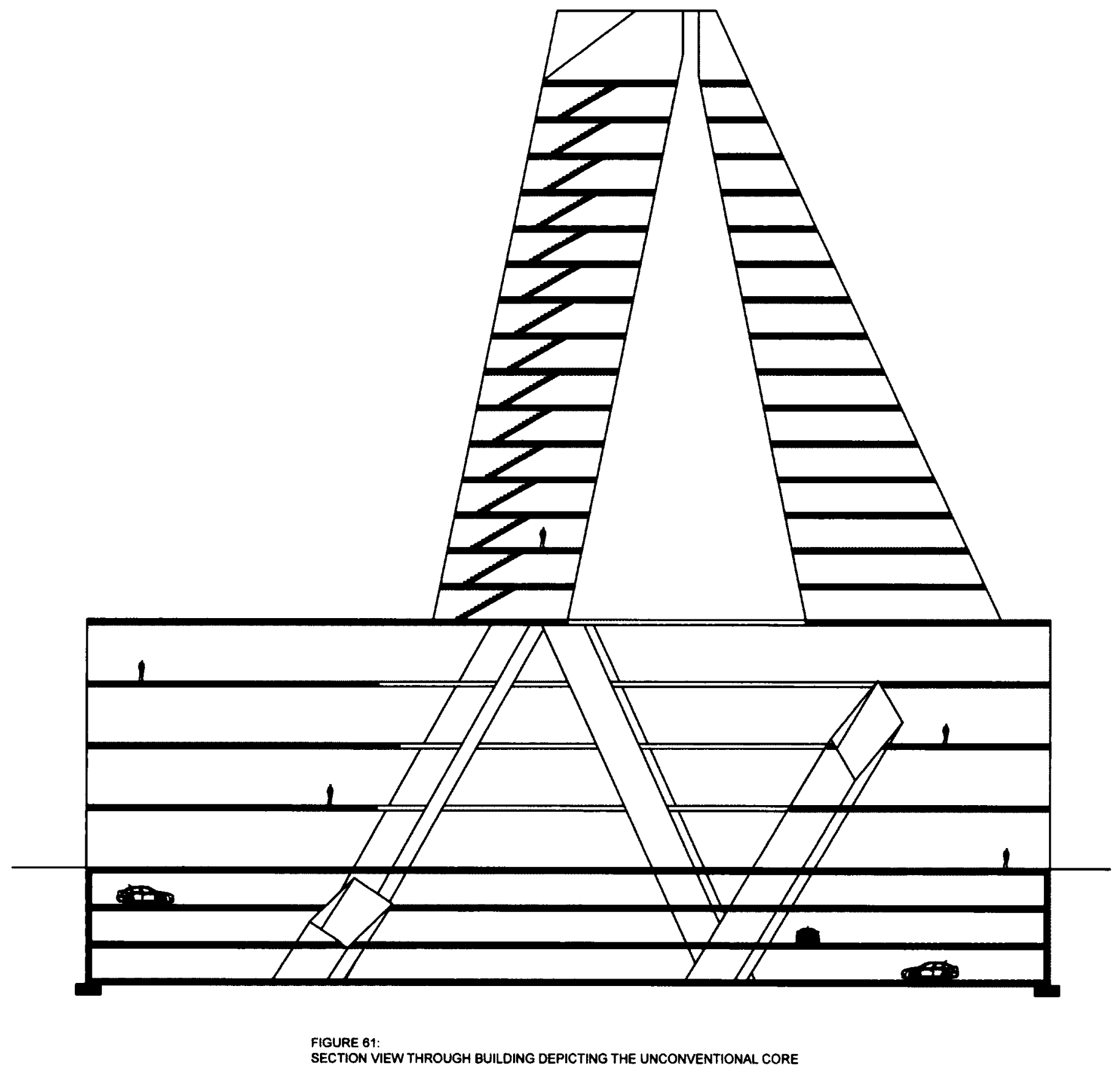


Architectural Implication targeting the third objective with customizable and transportable pods:

As discussed in previous sections, guests staying in a foreign city for an extended period of time would typically collect items from the local area as souvenirs. Providing a temporary space for these objects where they can be displayed is typically not feasible within the un-customizable hotel rooms. In addition to this, most hotels cannot cater to guests who prefer to customize their living space, and consequently individuality in temporary residences is impossible. The solution to both of these dilemmas is to implement a customizable and transportable pod within the hotel room where guests have the opportunity to modify spaces to suit their needs and changing preferences. The idea was partially inspired by Zittel's transportable units and Foster's moving gallery. This customizable space can be installed directly behind the bed as an alcove (shown in images in the following pages). Guests can use this enclave to display their personal items such as hanging of family photos, display of their recently purchased art works or books.

At the end of their stay, these pods can be used as a storage container where guests can place their belonging. The idea is to have this model replicated in other major cities around the world so that travelers can conveniently migrate from one part of the world to another with all their belongings with them without the headache. If needed, clients can also store these pods in the hotel if they plan to come back annually. 


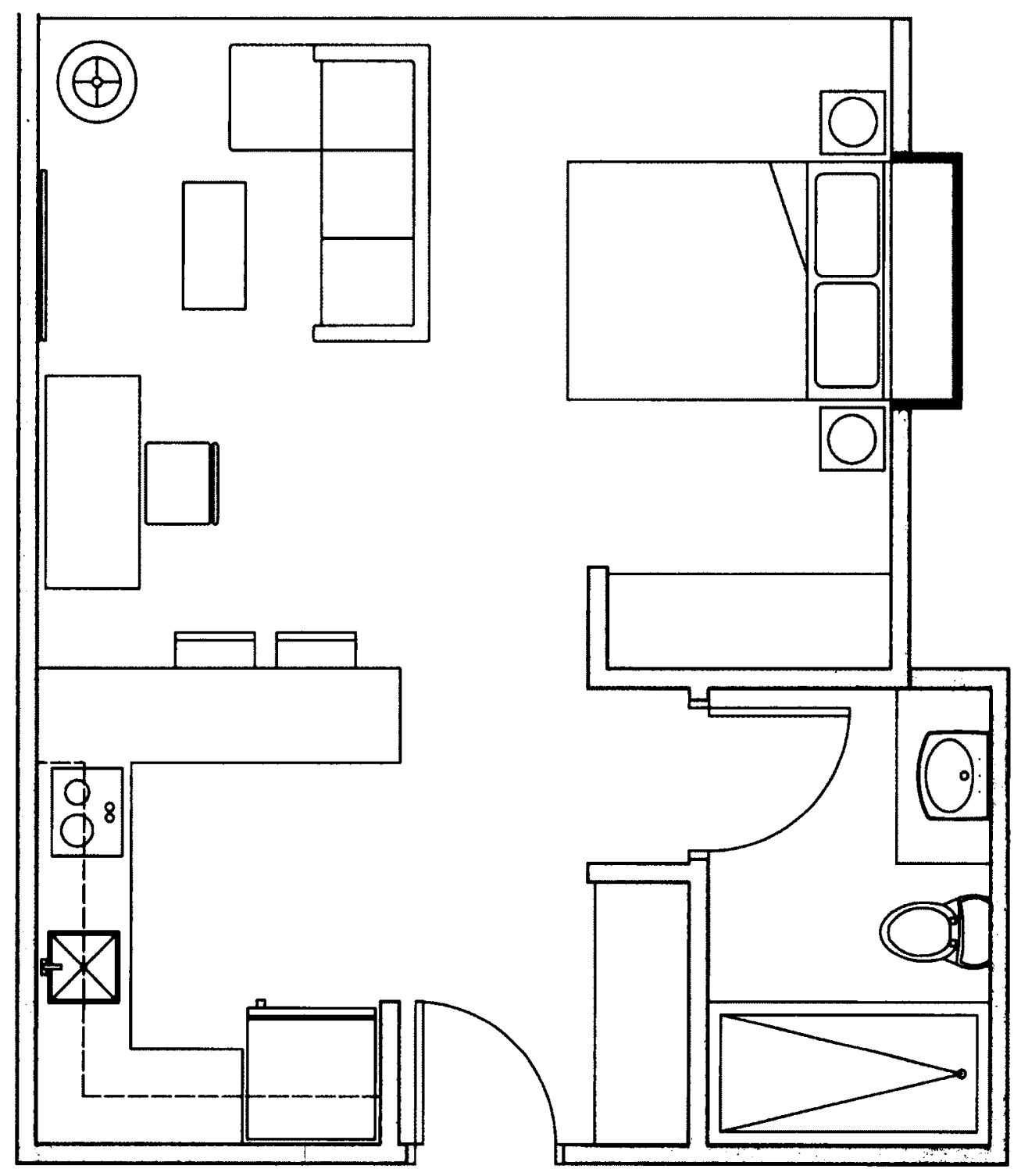

FIGURE 62

TYPICAL STUDIO ROOM WITH STORAGE POD HIGHLIGHTED IN RED 


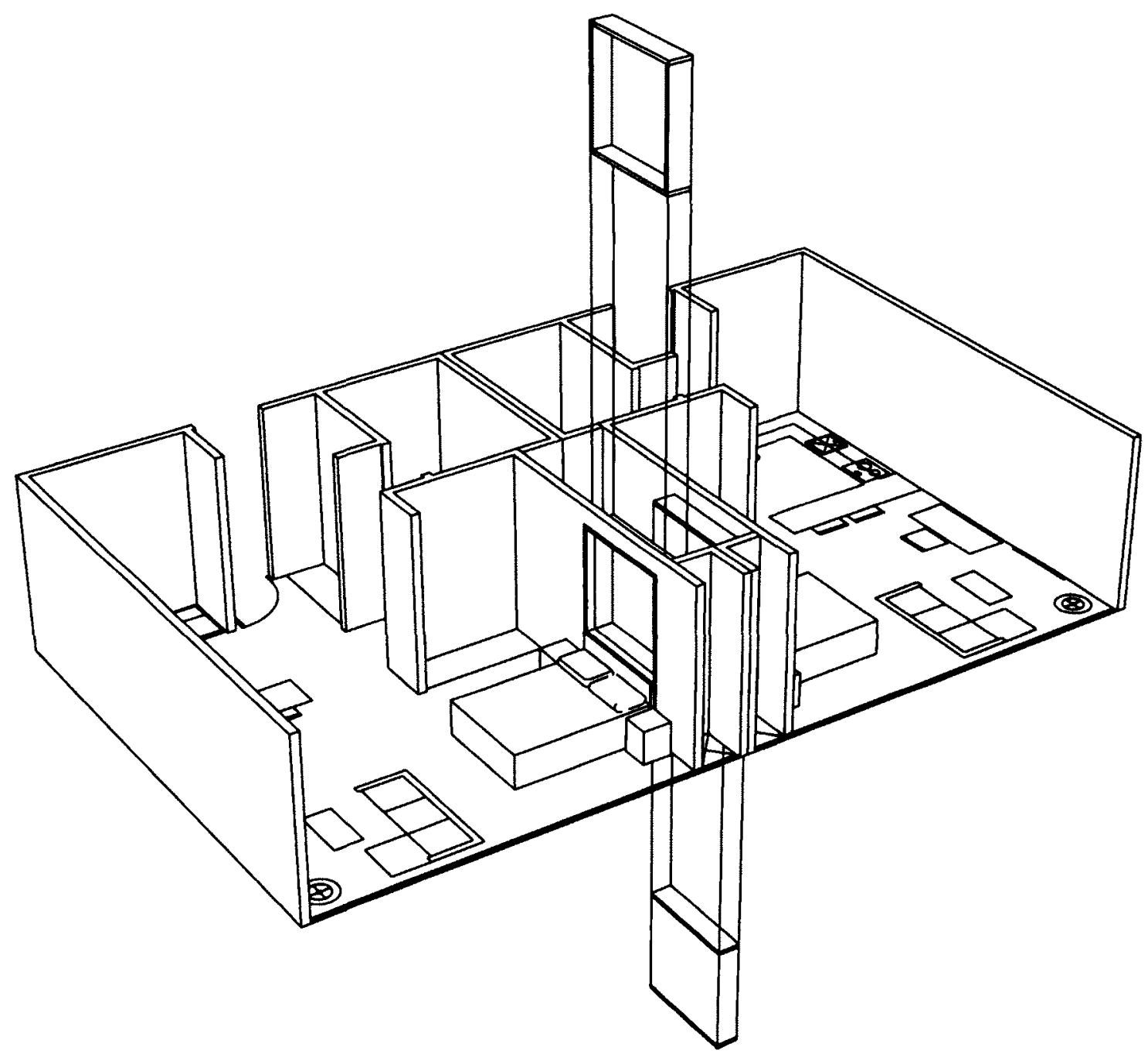

FIGURE 63:

STORAGE PODS ARE TRANSPORTED FROM DIRECTLY WTHIN THE HOTEL ROOM 


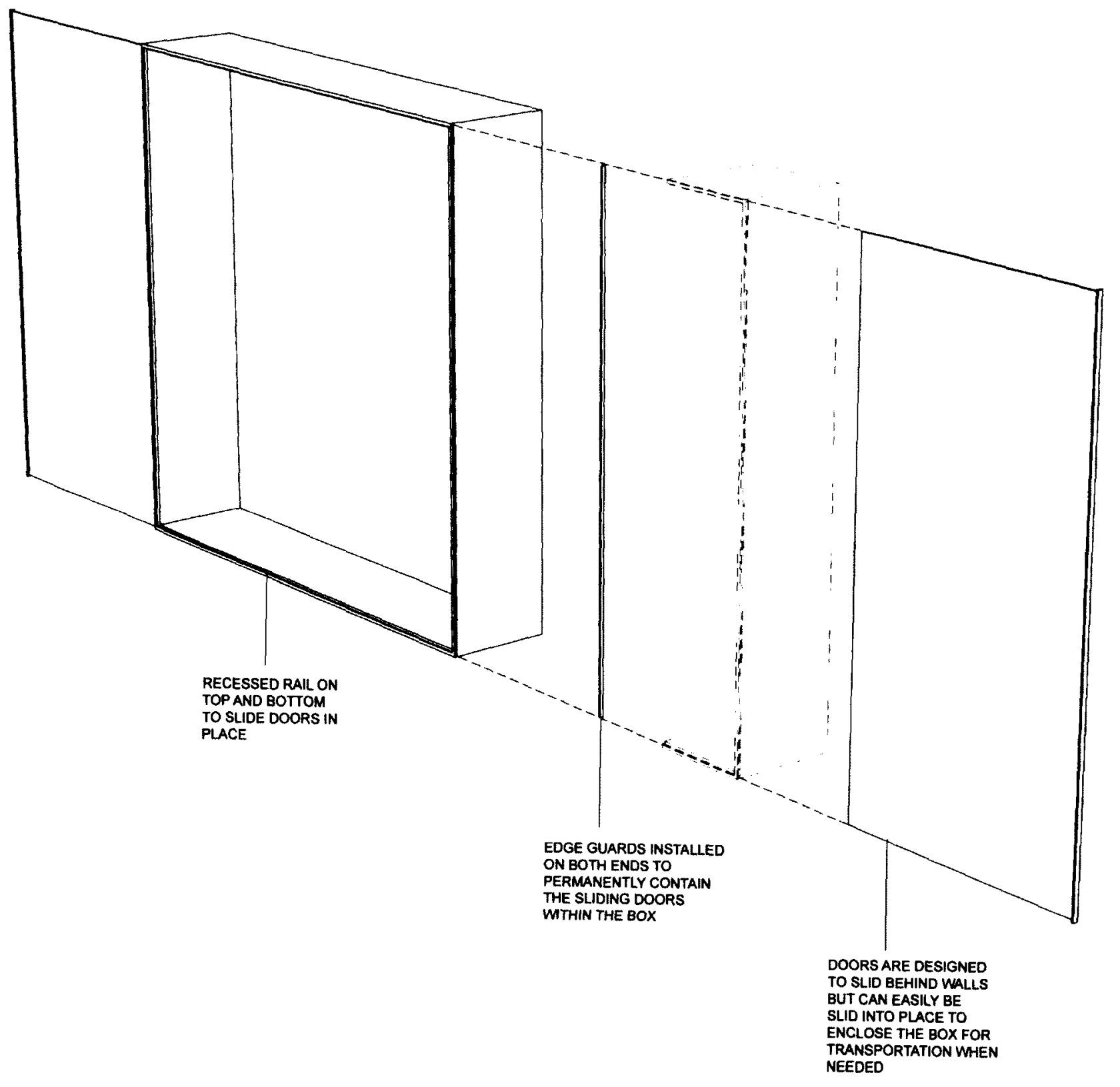

FIGURE 64

CONSTRUCTION OF THE TRANSPORTABLE POD (STORAGE BOX) 


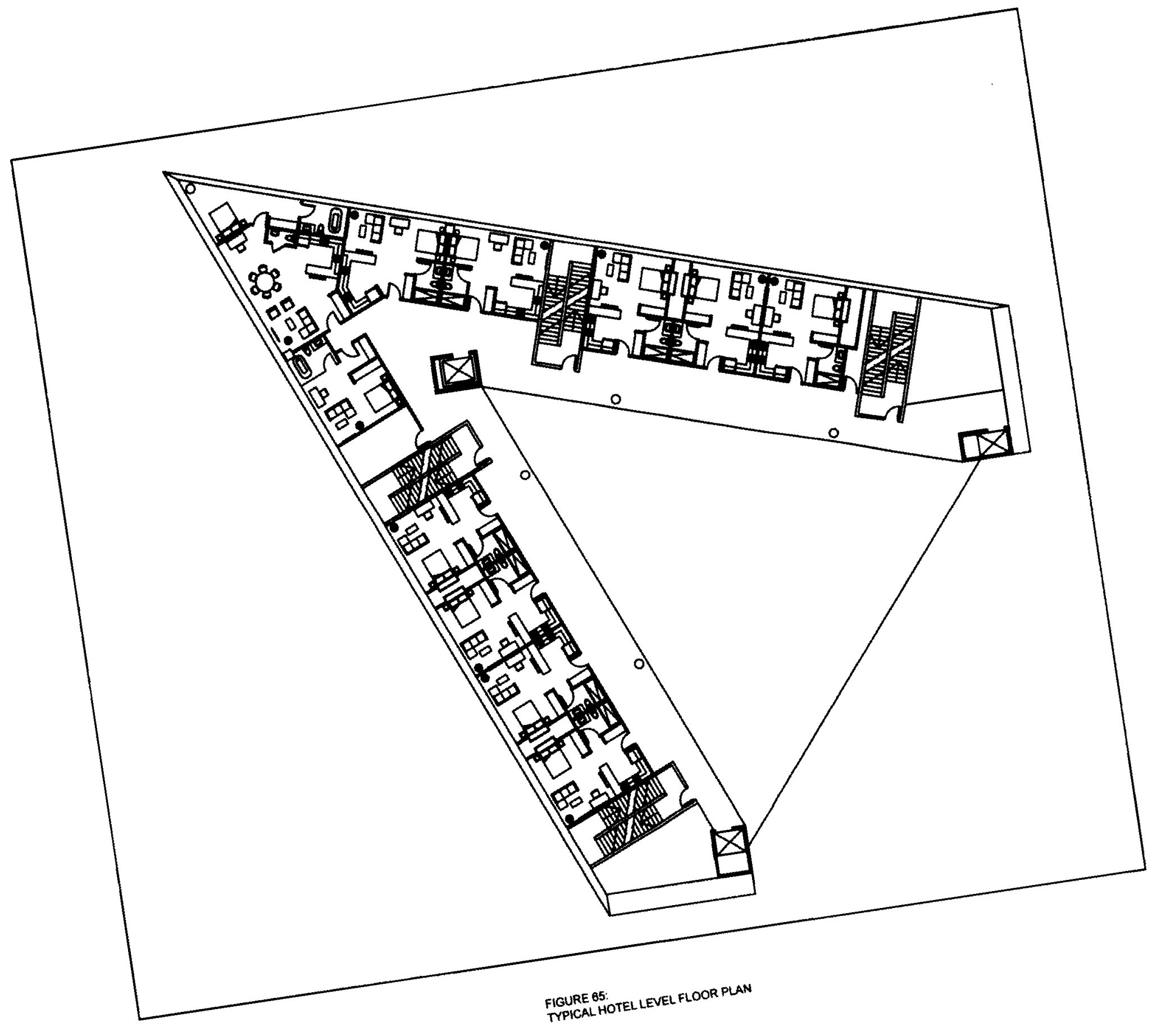




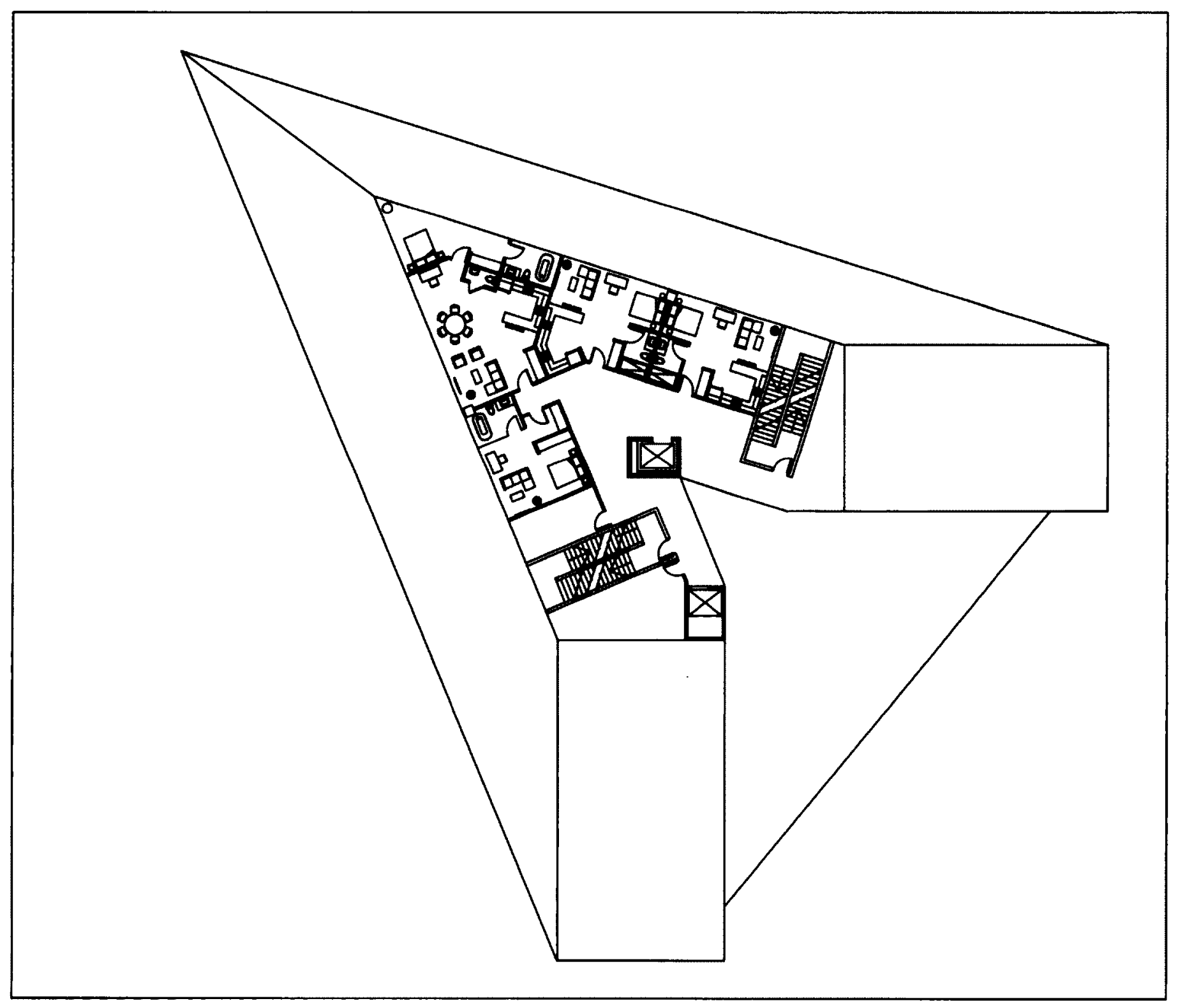

FIGURE 66

TOP LEVEL FLOOR PLAN 


\section{Post-Script}

The transportable container responded to the needs of the Creative Class by providing an efficient way to transport and store personal items. It eliminates potential waste created by disposal of accumulated goods over a lengthy period of stay. The user can neatly pack their belongings for reuse at another location. In reality, this model can potentially become a signature hotel brand with locations in major cities that specifically targets corporate executives and managers.

The idea of a Diagrid Core could be further refined if some of the sections can have an interchange of staircases, escalators and elevators. The innovativeness of the structure will certainly be inspiring for the Creative Class to circulate in, even if they have visited the building multiple times. The rarity of such a unique structure is stimulating for the mind. If the floor plates were completely solid (without an atrium to orient the user), the building could become quite challenging to navigate but would still provide an unrivaled spatial experience. This new Diagrid Core can also be applied successfully to other building typologies, specifically those in earthquake and hurricane prone areas to reinforce core structural stability.

When detailed elements such as ideas implemented from Le Meriden hotel (hotel key that can access local museums) combined with the architectural ideas presented in the portfolio, the proposed project vastly improves the existing architectural experience of hotels, produces exciting opportunities to explore and experience a new model of temporary living. 
The Rise of the Creative Class (2002) by Richard Florida was written more than a decade ago. Since then, cities and developers across North America had used his economic theory to implement, influence and advance city developments. It must be noted that cities that poured vast amounts of money into building his vision had largely failed. Attempts to recreate the successes of Silicon Valley in various cities were unsuccessful. ${ }^{38}$ Florida, published an article in The Atlantic Cities titled More Losers than Winners in America's New Economic Geography (Jan 30 2013), admitted that by building cities that mainly attract the Creative Class were unsustainable. In his words, "talent clustering provides little in the way of trickle-down benefits. ${ }^{\text {"39 }} \mathrm{He}$ concluded that even though cities were able to draw in the Creative Class to drive productivity and improve wages across different occupation (including blue collars), higher housing costs eventually resulted and forced the less skilled workers to relocate. This created an economically unsustainable model for a healthy city. ${ }^{40}$

Although Florida's theory was flawed in trying to spur economic growth in cities, the successes or failures of his vision was not of a major importance for this thesis. The significant contribution from referencing Florida's Creative Class was that he identified a unique group of people in our society. The focus on the lifestyle and pattern of the Creative Class/Bobos allowed for a different approach in architectural thinking and design. The focus led to new architectural innovation such as the Diagrid Core as presented in the portfolio. As architects, we should continue to strive to create new inspiring spaces for the public.

38 Florida, 304.

39-40 Richard Florida, More Losers than Winners in America's New Economic Geography, 30 Jan 2013, 5 May 2013 <http://www.theatlanticcities.com/ jobs-and-economy/2013/01/more-losers-winners-americas-new-economicgeography/4465/>. 
Interestingly, the status of the Bobos is very much alive and have gone international with the emergence of "China's Bobos Fever" as Jing Wang, who worked at a well-known global advertising agency Ogilvy in Beijing, had identified in her book Brand New China: Advertising, Media, Commercial Culture (2009). She commentated that there is currently a strong distaste for the nouveau rich in China by the general public and that the successful yet educated elites in China rather associate their new found bourgeois status with the word 'bohemians' as to lessen the perception of their materialistic lifestyle. ${ }^{41}$ In her marketing perspective, the influences of consumer products marketed in first tier cities would eventually trickle down to second and later third tier cities of China. This ripple effect had immense influence on people's desire for individualism and the chase for exquisite items. ${ }^{42}$ Unsurprisingly, there were even debates between intellectual groups on whether or not there is indeed a large group of Bobos in China. In any case, it is fascinating to see that the "Bobo fever was not only a popular cultural phenomenon but a marketing phenomenon". ${ }^{43}$

41 Jing Wang, Brand New China: Advertising, Media, Commercial Culture (Harvard University Press, 2009), 188.

42 Wang, 180-181.

43 Wang, 195. 


\section{Bibliography}

ArchDaily. Sperone Westwater Gallery / Foster + Partners. 2010 22-Sep. 2013 15-Dec $<$ http://www.archdaily.com/78827/sperone-westwater-gallery-foster-partners-2/>.

Borras, Montse. Hotel Spaces. Beverly: Rockport, 2008.

Brooks, David. Bobos in Paradise. New York: Simon \& Schuster, 2000.

Business Insider. The High-Flying Life of 'Homeless Billionaire' Nicolas Bergaruen. 2011 16-Dec. 2013 20-Jan <http://www.businessinsider.com/homeless-billionaire-nicolas-berggruen-2011-12?op=1>.

Caan, Shashi. Rethinking Design and Interiors: Human Beings in the built environment. London: Laurence King Publishing, 2011.

Central Intelligence Agency. ClA - The World Factbook. 2012 15-12 <https://www.cia. gov/library/publications/the-world-factbook/geos/sn.html>.

Esther Choi, Marrikka Trotter. Architecture at the Edge of Everything Else. Cambridge: MIT Press, 2010.

Florida, Richard. More Losers than Winners in America's New Economic Geography. 2013 30-Jan. 2013 5-May <http://uww.theatlanticcities.com/jobs-and-economy/2013/01/more-losers-winners-americas-new-economic-geography/4465/>.

Florida, Richard. The Rise of the Creative Class, Revisited. New York: Basic Books, 2012. 
Frank, Robert. The Homeless Billionaire - The Wealth Report - WSJ. 2008 19-May. 2013 20-Jan <http://blogs.wsj.com/wealth/2008/05/19/the-homeless-billionaire/>.

Groves, Kursty. I Wish I Worked There! A look inside the most creative spaces in business. West Sussex: John Wiley \& Sons, 2010.

Marriott. Marriott Residence Inn | Residence Inn Hotels. 2012 10-Dec <http://www. marriott.com/hotel-development/Residence-Inn.mi>.

Marriott. Marriott TownePlace Suites. 2012 10-December <http://www.marriott.com/hotel-development/Towneplace-Suites.mi>.

Sandoval-Strausz, A.K. Hotel:An American History. Devon: Duke \& Company, 2007.

Siegal, Jennifer. More Mobile: Portable Architecture for Today. New York: Princeton Architectural Press, 2008.

Singapore Toursim Board. Annual Report on Tourism Statistics 2009. Annual Report. Singapore: YourSingapore, 2010.

Starwood Hotels \& Resorts. Stanwood Hotels \& Resorts. 2012 03-12 <http://www.starwoodhotels.com/lemeridien/lm100/artist.html?id=FLORIDA>.

Strakosch, George and Robert Caporale. Vertical Transportation Handbook. 4th Edition. John Wiley \& Sons, 2010.

Wang, Jing. Brand New China: Advertising. Media, Cemmercial Culture. Harvard University Press, 2009. 


\section{Image Source}

Figure 1 Select images from - Borras, Montse. Hotel Spaces. Beverly: Rockport, 2008.

Figure 2 Brooks, David. Bobos in Paradise. New York: Simon \& Schuster, 2000, front cover.

Figure $3 \mathrm{http}: / /$ friendzon3.tumblr.com/image/24305390881

Figure $4 \mathrm{http}: / / \mathrm{ww} w$.theplan.it/J/images/stories/Riviste/The\%20Plan\%20027/027-6.jpg

Figure 5 http://www.zavodbig.com/sl/wp-content/uploads/2008/09/seijoville2-prev.jpg

Figure 6 http://www.zavodbig.com/sl/wp-content/uploads/2008/09/seijoville5-prev.jpg

Figure 7 Groves, Kursty. I Wish I Worked There! A look inside the most creative spaces in business. West Sussex: John Wiley \& Sons, 2010, 79.

Figure 8 Kursty, 77.

Figure 9 Kursty, 84

Figure 10 Kursty, 81

Figure 11 Kursty, 78.

Figure 12 Kursty, 76.

Figure $13 \mathrm{http}: / / w w w . w a l l p a p e r . c o m / g a l l e r y i m a g e s / 17053171 /$ gallery/03_Barcelona.jpg

Figure $14 \mathrm{http}: / /$ www.hotelchatter.com/story/2011/4/8/111735/3052/hotels/Another_Reason_

to_Collect_Hotel_Key_Cards\%3A_Le_Meridien's_Unlock_Art_Program

Figure $15 \mathrm{http} / / \mathrm{ww} w$.wallpaper.com/commercial/le-meridien/events/2012-06-\%204-an-art-in spired-dinner-and-private-view/5864

Figure 16 Sandoval-Strausz, A.K. Hotel: An American History. Devon: Duke \& Company, 2007, 29.

Figure 17 Sandoval-Strausz, 145.

Figure 18 Sandoval-Strausz, 146.

Figure 19 Sandoval-Strausz, 148. 
Figure $20 \mathrm{http} / / \mathrm{hw} w \mathrm{w} . \mathrm{sfgate} . c 0 \mathrm{~m} /$ politics/joegarofoli/article/Think-Long-panel-proposes-Cali fornia-tax-overhaul-2288794.php

Figure 21 Siegal, Jennifer. More Mobile: Portable Architecture for Today. New York: Princeton Architectural Press, 2008, 44-48.

Figure 22 http://minimalismissimple.com/wp-content/uploads/2012/10/9h_Nine-

Hours-Capsule-Hotel.jpg

Figure 23-25 Marriott TownePlace Suites. 2012 10-December <http://www.marriott.com/ho tel-development/Towneplace-Suites.mi>.

Figure 26-28 Marriott. Marriott Residence Inn | Residence Inn Hotels. 2012 10-12 <http://www. marriott.com/hotel-development/Residence-Inn.mis.

Figure 29 http://ad009cdnb.archdaily.net/wp-content/uploads/2010/09/1285171040-1680-nydcf030423-c-1000x750.jpg

Figure 30 http://ad009cdnb.archdaily.net/wp-content/uploads/2010/09/1285170987-1680-ny-ddsc6994-c-1000x666.jpg

Figure 31 http://ad009cdnb.archdaily.net/wp-content/uploads/2010/09/1285171027-1680-ny-ddsc7268-c-1000x666.jpg

Figure 32 http://ad009cdnb.archdaily.net/wp-content/uploads/2010/09/1285171256-sec tion-1000 $\times 1000 . j p g$

Figure 33 Strakosch, George and Robert Caporale. Vertical Transportation Handbook. 4th Edition. John Wiley \& Sons, 2010, 410.

Figure 34 Strakosch and Caporale, 402.

Figure 35 Strakosch and Caporale, 404.

Figure 36 Strakosch and Caporale, 403.

Figure 38-40 Statistic Data drawn from Singapore Toursim Board. Annual Report on Tourism Statistics 2009. Annual Report. Singapore: YourSingapore, 2010.

"Figures not listed above are self produced images, renderings, diagrams and/or drawings 